Research Article

\title{
Discrepancy between Forward and Reverse Seepage Characteristics in a Single Rough Fracture
}

\author{
Yulong Niu $\mathbb{D}^{1,2,3}$ Yuan Wang $\mathbb{D}^{1},{ }^{2}$ Zhiyu Sun, ${ }^{3}$ Jinghua Li, ${ }^{3}$ Xin Xiang, ${ }^{3}$ and Zhikui Wang ${ }^{4}$ \\ ${ }^{1}$ Postdoctoral Research Station of China Three Gorges Corporation, Beijing 100038, China \\ ${ }^{2}$ Key Laboratory of Ministry of Education for Geomechanics and Embankment Engineering, Hohai University, \\ Nanjing 210098, China \\ ${ }^{3}$ China Three Gorges Corporation, Beijing 100038, China \\ ${ }^{4}$ College of Civil and Transportation Engineering, Hohai University, Nanjing 210098, China
}

Correspondence should be addressed to Yuan Wang; wangyuan@hhu.edu.cn

Received 23 December 2020; Revised 22 February 2021; Accepted 9 March 2021; Published 22 March 2021

Academic Editor: Xinyu Ye

Copyright (c) 2021 Yulong Niu et al. This is an open access article distributed under the Creative Commons Attribution License, which permits unrestricted use, distribution, and reproduction in any medium, provided the original work is properly cited.

Under the uniform seepage boundary condition, the forward and reverse seepage flow rates will vary widely. In response to this phenomenon, this paper studies the mechanism of the difference in seepage characteristics between the forward and reverse directions from the fracture profile's roughness, Darcy and non-Darcy seepage, and distribution of eddy currents. First of all, wavelet transform was used to decompose and reconstruct the single rough fracture for 8 times, and then 9 fracture models with various roughness degrees were constructed. Then, Finite Volume Method was used to simulate the seepage in the original and approximate models of the Reynolds number varying from 0.001 to 1000 . The results show that the nonlinear seepage is necessary for the difference between the forward and reverse seepage characteristics of the single rough fracture. The mechanism of the discrepancy between forward and reverse nonlinear seepages is the diverse shapes and distribution of the eddy current generated by the forward and reverse seepage. The secondary roughness provides space for the existence and development of the eddy current. The secondary roughness is the geometric basis of the discrepancy between the forward and reverse seepage characteristics.

\section{Introduction}

In fractured rock masses, fractures act as the dominant seepage channels controlling the entire rock mass's hydraulic properties compared to the matrix with low permeability [1]. The study of hydraulic properties of rock fractures involves the transport of pollutants [2], geological storage of $\mathrm{CO} 2$ [3], geothermal and petroleum resources development and utilization $[4,5]$, prediction of seepage flow rate [6], and many other engineering fields. The single rough fracture is the basic unit of the rock fracture network. Thoroughly studying the fluid flow in the single rough fracture is the basis of understanding the fluid flow and solute transport in fractured rock masses $[7,8]$.

Both the porous medium and the fractured rock mass have the feature of seepage anisotropy [1], and so does the single rough fracture. For example, the studies of Thompson and Brown [9], Grasselli et al. [10], and Cao et al. [11] show that the anisotropy of the fracture surface roughness is the main cause of the seepage anisotropy ( $X$-axis and $Y$-axis). Yeo et al. [12], Auradou et al. [13], and Huang et al. [14] studied the effect of fracture space variation on seepage anisotropy. However, besides the phenomenon that the seepage characteristics of the $X$-axis and the $Y$-axis are different, the seepage characteristics in the forward and reverse directions of the $X$-axis (the $+X$-direction and the $-X$-direction) are also different. For example, Grasselli et al. [10] performed a single rough fracture seepage experiment in the $+X$-direction and $-X$-direction, respectively, with Reynolds numbers varying from 5 to 150 . The experimental results show that the equivalent hydraulic aperture decreases as the Reynolds number increases. Moreover, the equivalent 
hydraulic aperture in the $+X$-direction is greater than that of $-X$-direction under the same Reynolds number. Boutt et al. [15] studied the transport of colloids in $+X$-direction and $-X$-direction in single rough fractures through numerical simulation, which confirmed the discrepancy between the forward and reverse seepages in single rough fractures. Xie et al. [16] found that the flow rate of $+X$-direction and $-X$ direction was different under shear displacement through numerical simulations related to the local eddy current. Cardenas et al. [17] studied eddy currents' sensitivity to the fluid flow in the $+X$-direction and $-X$-direction and the effect of eddy current on solute transport. They also pointed out that the anisotropy of $3 \mathrm{D}$ fractures and the directional transport of 2D fractures are fracture fluid mechanics studies' weaknesses. The laboratory experiments and numerical simulations show that the seepage characteristics in the forward and reverse directions are different in a single rough fracture, and it is related to the eddy current in the fracture. Nevertheless, how the eddy current affects the forward and reverse seepage characteristics and how the fracture's roughness affects eddy currents need to be further studied.

Patton [18], Lee et al. [19], Xie et al. [20], and other authors hold that the roughness of rough fractures exists as a multiple-scale and shows a characteristic of self-similarity. The International Society for Rock Mechanics (ISRM) divides the roughness of rock surfaces (joint or fracture) into large-scale fluctuations (also known as primary roughness) and small-scale fluctuations (also known as secondary roughness) [21]. Jing et al. [22], Kana et al. [23], and Yang et al. [24] studied the role of primary roughness and secondary roughness in the shear process of fractures. Within small displacement, the shear process is controlled by secondary roughness, and, within large displacement, the shear process is controlled by primary roughness. The control effect of roughness on the fluid flow in fractures is widely recognized. But the influence of the primary and secondary roughness on the seepage of the fracture is still in the stage of exploration; only Sharifzadeh [25], Zou et al. [26], Zou et al. [27], Wang et al. [28], Dou et al. [7], and other few scholars carried out related researches. Among them, Zou et al. [26] and Zou et al. [27] found that high-frequency secondary roughness is the main reason (except for Reynolds number) for the dynamic evolution of the eddy current, and the higher the high-frequency roughness, the more obvious and complex the eddy current region. Wang et al. [28] show that the primary roughness mainly controls the flow path and large-scale pressure distribution, while the secondary roughness controls the nonlinear seepage characteristics of the local-scale fluid flow. Meanwhile, as the pressure gradient increases, the secondary roughness increases the complexity of the local velocity distribution by creating and expanding eddy currents and recirculation regions. Dou et al. [7] found that the secondary roughness significantly enhanced the nonlinear flow (i.e., eddies and tortuous streamlines) and the non-Fickian transport. It can be observed in the existing research results that secondary roughness (high-frequency roughness) has a decisive effect on the occurrence and development of nonlinear seepage and eddy current regions. But whether the secondary roughness (high-frequency roughness) is related to the discrepancy between the forward and reverse seepage characteristics still needs further exploration.

In summary, the discrepancy between the forward and reverse seepage characteristics of the single rough fracture remains to be discussed and studied. In order to study the above problems, the wavelet transform is used to decompose and reconstruct the single rough fracture profile generated by Brazil splitting test. The fracture profiles at different scales (different decomposition levels) are obtained, and the corresponding models are built. Then FVM (Finite Volume Method) was used to simulate seepage in forward and reverse directions under different Reynolds numbers. The mechanism of the discrepancy between forward and reverse seepage characteristics of the single rough fracture is analyzed from the aspects of equivalent hydraulic aperture, nonDarcy coefficient, and local seepage field. The correlation between inconsistent roughness in the forward and reverse directions and the inconsistent seepage characteristics is also discussed.

\section{Fracture Profiles at Different Scales}

For multiscale analysis of $2 \mathrm{D}$ rough fracture profiles, the Fourier transform [29] and the wavelet transform [30] are the most frequently used tools in signal processing disciplines. The geometry of the natural fracture profile can be viewed as a nonstationary signal. In the Fourier transform, there are some limitations to the analysis of nonstationary signals because only the stationary signal can be processed. Meanwhile, the wavelet transform can better handle the nonstationary signal, and the wavelet transform method is advantageous to analyze the multiscale effect of surface roughness on fluid flow through rock fractures [26-28, 31]. Therefore, the wavelet transform is used to build the profile of the single rough fracture at different scales.

2.1. Building Single Rough Fracture Profiles. In this paper, the rough fracture surface of coarse-grained granite is used as the original surface to create the fracture models at different scales through the wavelet transform. The size of the standard cylindrical rock sample is $100 \mathrm{~mm} \times 50 \mathrm{~mm}$. A binocular 3D laser scanning system was used to scan the Brazilian splitting test's fracture surface. The binocular 3D laser scanning system's accuracy is $\pm 20 \mu \mathrm{m}$, and the scanning interval is set at $0.1 \mathrm{~mm}$ on $X$-axis and $0.2 \mathrm{~mm}$ on $Y$-axis to obtain surface elevation data of the sample. We can get the digital fractured surface the same as the entire fracture surface through the points scanned. The vertical section of the middle of the specimen was taken as the sample's typical fracture model's original profile. The entire process of constructing an accurate rough fracture profile is shown in Figure 1.

2.2. Basic Theory of the Wavelet Transform. The single rough fracture profile has characteristics of multiple scales and is similar to signals. Therefore, the $2 \mathrm{D}$ single rough fracture 


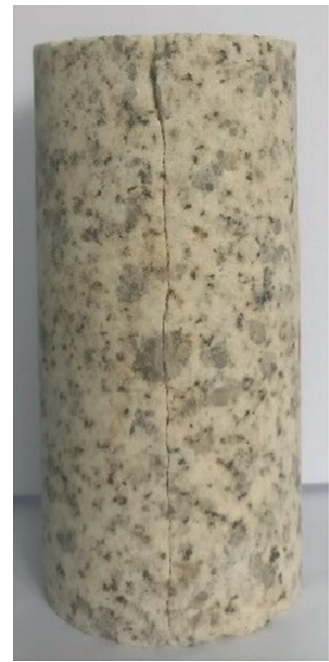

(a)

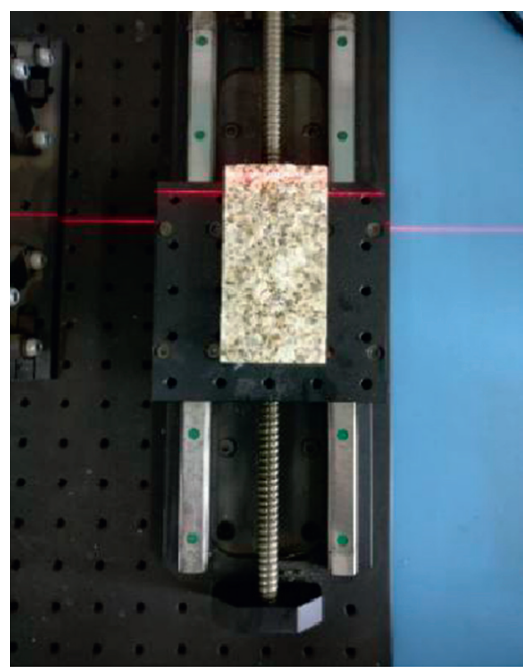

(c)

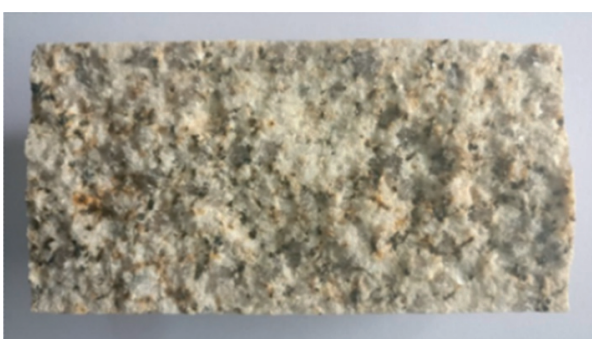

(b)

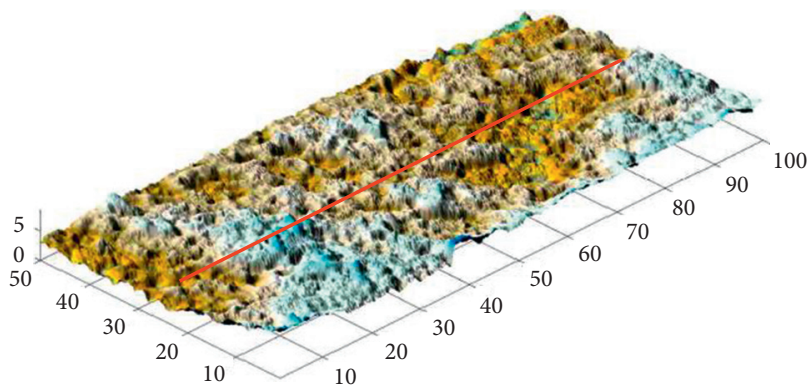

(d)

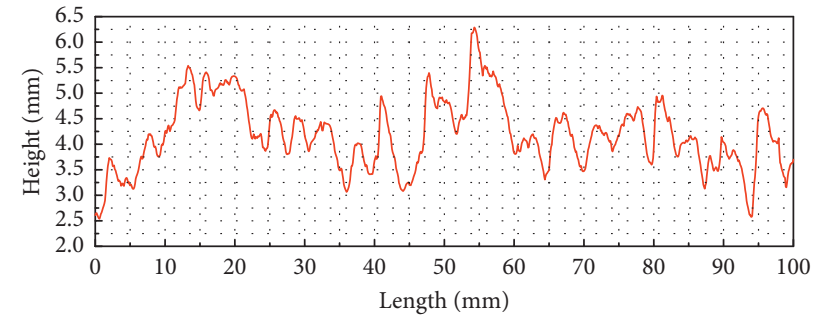

(e)

FIGURE 1: Generating process of the single fracture profile of coarse-grained granite: (a) specimen after Brazilian splitting test; (b) fracture surface formed by splitting; (c) 3D laser scanning; (d) fracture surface generated by scanning; (e) single rough fracture profile.

profile can be regarded as a signal function $f(t)$ to be processed, where $f$ represents the vertical height of fluctuations and $t$ represents the horizontal distance along the fracture. When applying the wavelet transform, equation (1) is used.

$$
\begin{aligned}
W_{f}(a, b) & =\left\langle f, \psi_{a, b}\right\rangle=\frac{1}{\sqrt{|a|}} \int_{-\infty}^{+\infty} f(t) \overline{\psi\left(\frac{t-b}{a}\right)} \mathrm{d} t, \\
\psi_{a, b}(t) & =\frac{1}{\sqrt{|a|}} \psi\left(\frac{t-b}{a}\right), \quad a, b \in R ; a \neq 0,
\end{aligned}
$$


where $\psi(t)$ is the mother wavelet function; $\psi_{a, b}(t)$ is a wavelet sequence function; $a$ is the scale factor; $b$ is the translation factor. Therefore, the wavelet transform can be seen as a convolution of the signal function $f(t)$ and a wavelet sequence function $\psi_{a, b}(t)$ with the bandpass filter. A detailed discussion of the wavelet transform can be found in Zou et al.'s work [27].

Before performing the wavelet transform, the appropriate mother wavelet function needs to be chosen first. Which wavelet to be chosen as the mother wavelet mainly depends on the application requirements [32]. Mirzaeian [33] pointed out that high-order Daubechies wavelets are more suitable for processing surface roughness than other wavelets in wavelet libraries. Sharifzadeh [25], Zou et al. [26], Zou et al. [27], and Wang et al. [28] used Db8 wavelets in the Daubechies wavelet series to process $2 \mathrm{D}$ rough single fracture profiles or 3D single rough fracture surfaces. Therefore, the Db8 wavelet was used as the mother wavelet function in the wavelet transform.

2.3. Multiscale Decomposition of Single Rough Fracture Profiles. In this section, the wavelet transform and reconstruction will be performed on the single rough fracture in Figure 1(e) as the original fracture model $S$. The profile of the single rough fracture is defined as $f(x), x \in[0, L]$, where $L$ represents the length of the profile along the $X$-axis. In this paper, $L=100 \mathrm{~mm}$. $F$ is the height of the measured profile at the position of $x$. For the fracture profile, the Mallat algorithm is used for eight-level decomposition and reconstruction [34]. The approximate models are labeled as $\mathrm{A} 1-\mathrm{A} 8$, and the detailed models are labeled as D1-D8. The specific decomposition process labeled can be found in Zou et al.'s work [27].

Figure 2 shows the approximate models $\mathrm{Ai}$ and the detailed models Di of each decomposition level. The approximate models Ai represents the geometry that plays a dominant role in the fracture profile with a low frequency, large wavelength, and large amplitude. The detailed models Di represents small-scale ups and downs with a high frequency, small wavelength, and small amplitude compared with the approximate profile. As the level of decomposition increases, it can be seen that the wavelength and amplitude of Di gradually increase, varying from $0.05 \mathrm{~mm}$ in the first level to more than $0.5 \mathrm{~mm}$ in the eighth level. So, it gradually shows a large-scale characteristic (low frequency and large wavelength), which is similar to the entire profile. At the same time, as the level of decomposition increases, the approximate profile (blue line) gradually loses the original profile information compared with the entire profile, leading to the larger wavelength and smaller amplitude, and it slowly turns smooth and parallel.

According to Figure 2, the approximate profile A4 shape remains the same as the original profile $S$. The shape of the approximate profile A5 is different from the original profile $\mathrm{S}$. The fluctuation difference $\Delta$ (the highest vertical height minus the lowest vertical height) under different decomposition levels is counted, as shown in Figure 3. The inflection point of the curve of fluctuation difference $\Delta$ and decomposition levels is at level four. The value of fluctuation difference $\Delta$ before and after the fourth level changes significantly. Therefore, in this paper, the approximate profile A4 is taken as the primary roughness (wavy fluctuation structure). The original profile $S$ minus the approximate profile $\mathrm{A} 4(D 1+\mathrm{D} 2+D 3+\mathrm{D} 4)$ is considered as the secondary roughness (fine roughness structure).

The wavelet transform is used to decompose and reconstruct the rough fracture profiles, separating the fractured profiles into the generally approximate profiles and the locally detailed profiles in a unique way. It establishes the one-to-one relationship between locally detailed profiles, approximate profiles, and the original profile, making the roughness of the fracture profile unique and accurate at different scales [7, 26-28]. It also provides a new solution for studying the geometric characteristics of the fracture roughness at different scales. At the same time, it also lays the geometric foundation for analyzing the effect of the detailed profile of rough fractures significantly when the secondary roughness affects the discrepancy between the forward and reverse hydraulic characteristics.

\section{Numerical Simulation of the Forward and Reverse Seepage in the Single Rough Fracture}

3.1. Governing Equations and Numerical Methods. The N-S equation and the continuity equation (momentum conservation and mass conservation) are often used to describe fluid flow in fractures quantitatively [35-37]. The equation of momentum conservation and mass conservation of the incompressible Newtonian fluid flow in a stable state can be written as follows:

$$
\begin{aligned}
\rho(\vec{u} \cdot \nabla) \vec{u} & =-\nabla P+\mu \nabla^{2} \vec{u}, \\
\nabla \cdot \vec{u} & =0,
\end{aligned}
$$

where $\rho$ is the density of the fluid, $\vec{u}$ is the velocity vector, $\mu$ is viscosity, $P$ is the total pressure, $\nabla$ is Hamiltonian operator, and $\nabla^{2}$ is Laplace operator.

Numerical methods are widely used to solve the $\mathrm{N}-\mathrm{S}$ equation to study the flow characteristics in rough fractures because it cannot be solved directly [15, 17, 35, 37-39]. In this paper, Fluent 16.0 developed based on FVM code was adopted to simulate the seepage in rough fractures. Javadi et al. [36], Qian et al. [40], Qian et al. [41], and Liu et al. [42] have verified the reliability of the software and studied the Darcy or non-Darcy fluid flow in the fracture. In this study, DNS (direct numerical simulation) and RANS (Reynolds average Navier-Stokes equation) are used for the simulation of laminar and turbulent fluid flow, respectively, and the standard $k-\varepsilon$ model is used to simulate turbulent fluid flow. The detailed theory can be seen in Javadi et al.'s work [36].

3.2. Calculation Area and Boundary Conditions. In order to study the influence of the detailed profile on the forward and reverse seepage characteristics of single rough fractures, the original profile model $\mathrm{S}$ and the eight approximate profile models $\mathrm{Ai}$ are moved upward by $0.5 \mathrm{~mm}$, respectively, 


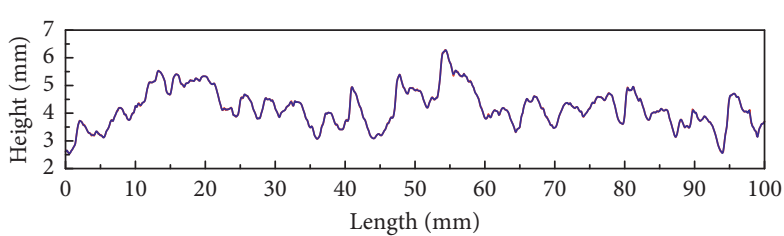

$-\mathrm{S}$

- A1

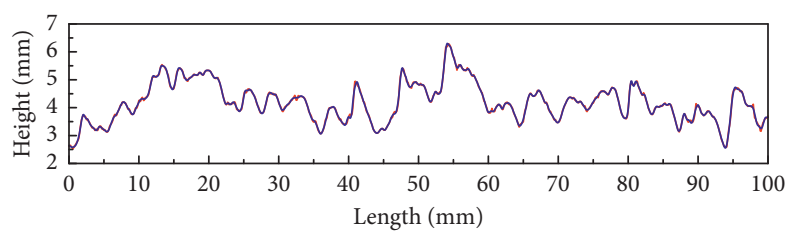

$\mathrm{S}$
$-\mathrm{A} 2$

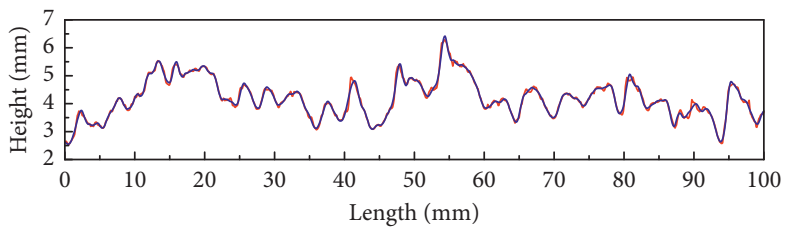

$-\mathrm{S}$

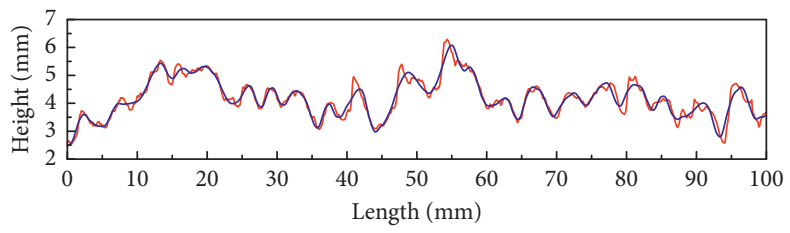

- S

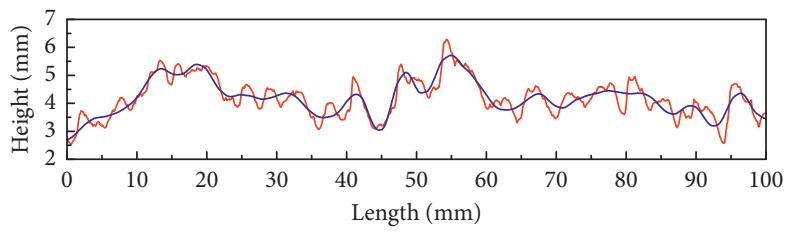

$-\mathrm{S}$

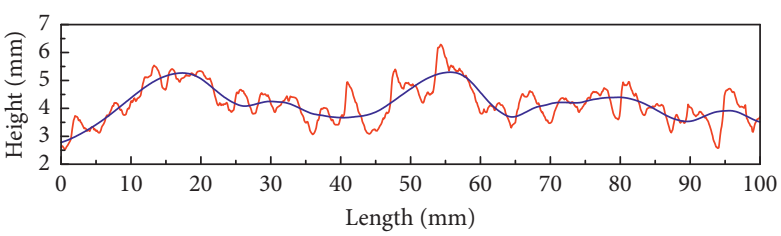

$-\mathrm{S}$

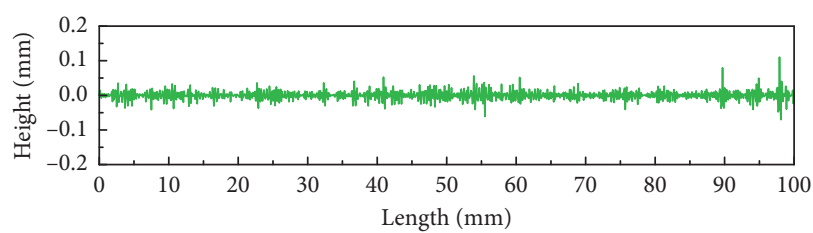

$-\mathrm{D} 1$

(a)

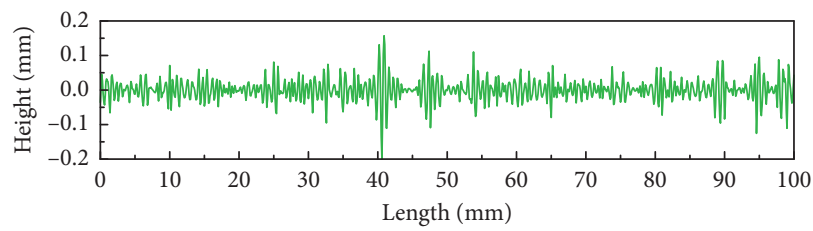

$\longrightarrow$ D2

(b)

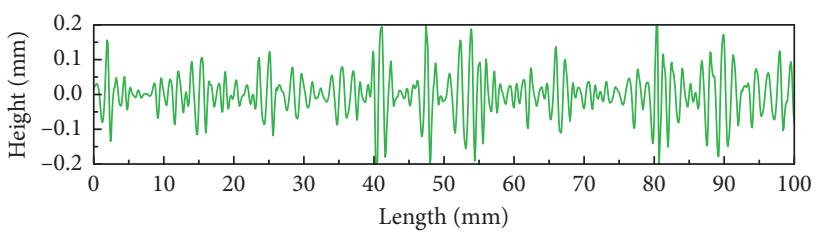

- D3

(c)

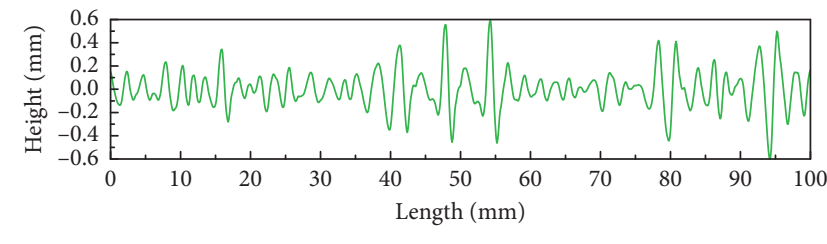

$-\mathrm{D} 4$

(d)

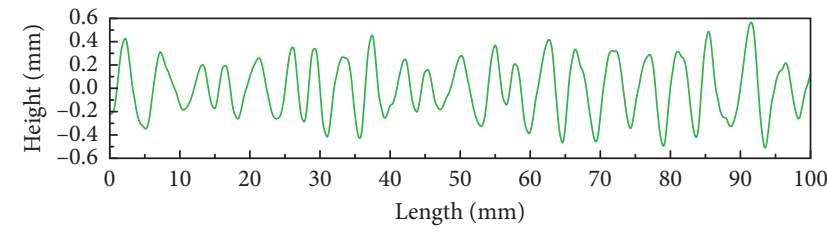

- D5

(e)

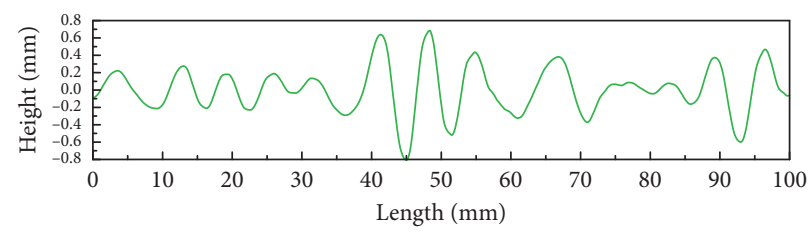

— D6

(f)

Figure 2: Continued. 


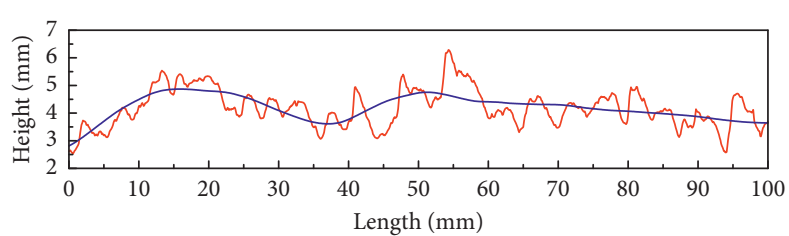

$-\mathrm{s}$

$-\mathrm{A} 7$

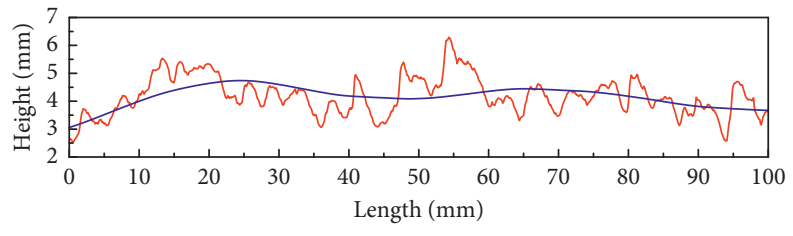

$-\mathrm{S}$

$-\mathrm{A} 8$

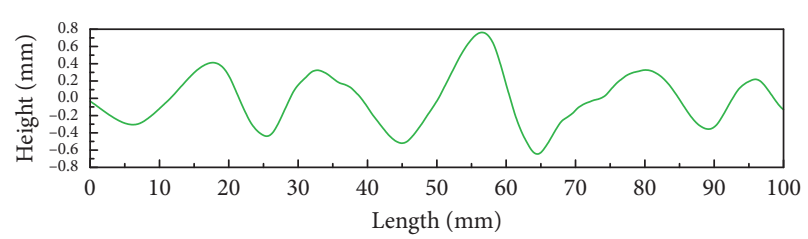

$-\mathrm{D} 7$

(g)

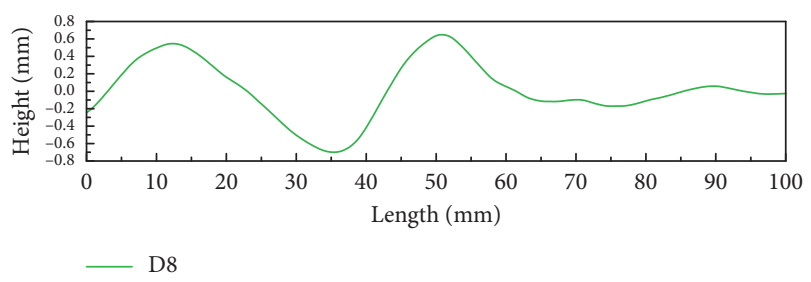

(h)

Figure 2: The approximate profiles Ai and detailed profiles Di under different decomposition levels: (a) Level 1. (b) Level 2. (c) Level 3. (d) Level 4. (e) Level 5. (f) Level 6. (g) Level 7. (h) Level 8.

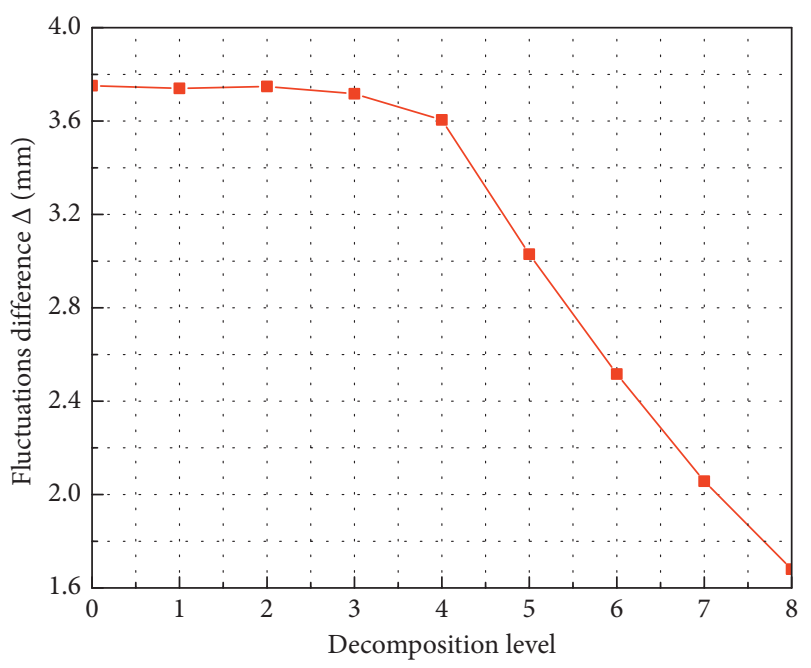

Figure 3: The variation of fluctuations difference $\Delta$ with decomposition level.

building nine rough fracture models at different scales (different decomposition levels). Furthermore, the model is discretized by a quadrilateral mesh. The average side length of the element is $0.02 \mathrm{~mm}$, which is the same as the fracture surface's scanning accuracy.

For comparative studies, the same hydraulic boundary conditions are assigned to each fracture model. The entrance boundary is set as the velocity inlet boundary. The flow rate values corresponding to 13 sets of Reynolds number values $(0.001,0.005,0.01,0.05,0.1,0.5,1,5,10,50,100,500$, and 1000) are taken. These Reynolds numbers are chosen because they are common in laboratory conditions and water conservancy project [27]. The Reynolds number is defined as the ratio of inertial force to viscous force. For fluid flow in rough fractures, it is given by Zimmerman et al. [43], Javadi et al. [44], and Zou et al. [27] as follows:

$$
\operatorname{Re}=\frac{\rho Q}{\mu w}=\frac{\rho v e_{\text {in }}}{\mu},
$$

where $Q$ is the flow rate, $w$ is the width perpendicular to the direction of the fracture model surface (in 2D conditions, $w=1 \mathrm{~m}), v$ is the mean value of the velocity along the $+X$-direction, $e_{\text {in }}$ is the aperture of the inlet boundary, the density of water $\rho=1000 \mathrm{~kg} / \mathrm{m}^{3}$, the coefficient of dynamic viscosity $\mu=1 \times 10^{-3} \mathrm{~Pa} \cdot \mathrm{s}$, and the effect of the gravity is ignored.

In order to compare and analyze the influence of flow direction on the seepage field, the left side is set as the inlet and the right side is set as the outlet when simulating forward seepage. On the contrary, when simulating reverse flow, the right side is set as the inlet and the left side as the outlet. In this paper, the fracture profile is vertically translated upward to create a fracture model with seepage channels, so $e_{\text {in }}$ of all fracture models equals $0.5 \mathrm{~mm}$. The velocity of entrance boundary is set at a series of values between $2.00962 \times 10^{-6} \mathrm{~m} / \mathrm{s}$ and $2.00962 \mathrm{~m} / \mathrm{s}$, making the Reynolds number equal 0.001, 0.005, 0.01, 0.05, 0.1, 0.5, 1, 5, $10,50,100,500$, and 1000 . At the same time, the exit boundary of all fracture models is set at zero pressure. The fracture models' upper and lower boundaries are set as boundary conditions without fluid flow and displacement.

\section{Evolution of the Discrepancy between Forward and Reverse Seepages}

4.1. Evolution of Equivalent Hydraulic Aperture. The simplest and most well-known model for describing fluid flow in a single rock fracture is the smooth and parallel plate model, which simplifies the rock fracture into two smooth parallel plates with a gap between the upper and lower surfaces. When the flow rate is low, the state of the fluid flow in the smooth and parallel plate model is laminar. In the 
incompressible Newtonian fluid flow, the quantitative relationship (equation (5)) between the flow rate $Q$ and the cubic of the aperture $e$ can be obtained under the constant pressure gradient, which is the famous cubic law:

$$
Q=-\frac{w e^{3}}{12 \mu} \nabla P .
$$

Because the natural fracture surface is far from the smooth plane, equation (5) needs to be revised before the cubic law is applied to rough fractures, where the aperture will be replaced by the equivalent hydraulic aperture $e_{h}$. The equivalent hydraulic aperture $e_{h}$ is acquired based on the Darcy flow state's back-calculation, reflecting the rough fracture's discharge capacity in the Darcy flow state. The cubic law is used to calculate the equivalent hydraulic aperture $e_{h}$ under all selected Reynolds number, and it can also be used to quantitatively describe the discharge capacity of the rough fracture under different Reynolds numbers $[26,28,45]$. In order to reflect the effect of fracture roughness and nonlinear seepage on the water conductivity of fracture, the equivalent hydraulic aperture is normalized (the ratio of the equivalent hydraulic aperture $e_{h}$ to the average mechanical aperture $e_{m}$ ). Li and Jiang [46], Qian et al. [47], and Zhang et al. [48] have established the relationship between $e_{m} / e_{h}$, roughness, and Reynolds number Re. Besides, under the same roughness, $e_{m} / e_{h}$ will increase with the increase of Re. Cao et al. [11] also proved by experiments that increasing hydraulic pressure decreased hydraulic conductivity and $e_{m} / e_{h}$ discrepancy. Briggs et al. [45] define $e_{h} / e_{m}$ as the relative effective aperture, and the average mechanical aperture $e_{m}$ in this paper is $0.5 \mathrm{~mm}$.

When the Reynolds number varies from 0.001 to 1000 , the trend of the relative effective aperture $e_{h} / e_{m}$ of the original profile model and the eight approximate profile models is shown in Figure 4. When the Reynolds number is between 0.001 and 10 , the values of $e_{h} / e_{m}$ of all models are the same in all models (meaning the equivalent hydraulic aperture $e_{h}$ is a constant). So, the fluid state at this time should be within the laminar flow. When the Reynolds number is over 10 , the value of $e_{h} / e_{m}$ of all models begins to decrease, indicating that the relationship between flow rate $Q$ and pressure gradient $\nabla P$ deviates from the cubic law. The fluid flow has entered a nonlaminar state (nonlinear flow). As the Reynolds number increases, the value of $e_{h} / e_{m}$ decreases gradually, suggesting that as the Reynolds number increases, the characteristics of nonlinearity in the fracture seepage increase. This is consistent with the research results of Zhang et al. [48]. Qin et al. [49] found that the modified cubic law can be well adopted in the test when the hydraulic pressure is $0.1 \mathrm{MPa}$, but $R^{2}$ of the fitting lines decreases with the increase of hydraulic pressure. The influence of nonlinear flow in the crack increases with the increase of hydraulic pressure, which narrows the effective water passage and then reduces the actual flow capacity of the crack. Meanwhile, as the number of decomposition levels increases, the detailed profiles at different scales are gradually removed, and the value of $e_{h} / e_{m}$ in the Darcy flow state gradually increases. The value of $e_{h} / e_{m}$ at the 7 th and 8 th

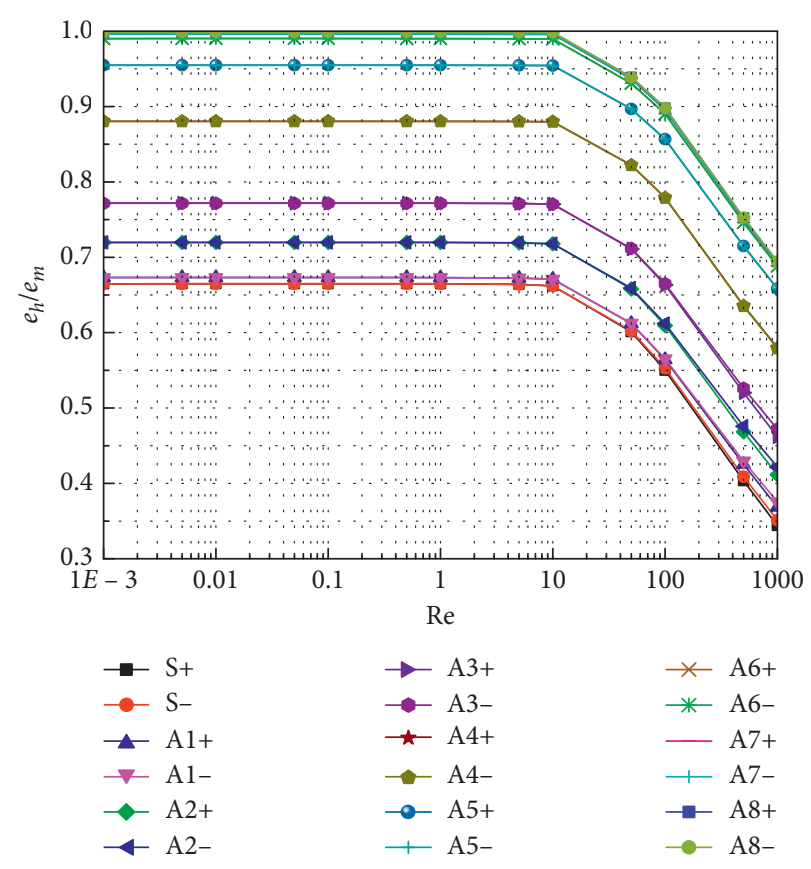

FIgURE 4: Variation of the relative hydraulic aperture $e_{h} / e_{m}$ with Reynolds number under different decomposition levels in the approximate profile models ( $\mathrm{Ai}+$ and $\mathrm{Ai}-$ represent the calculation results of model $\mathrm{Ai}$ in the forward and reverse directions, respectively).

decomposition levels is approaching 1 , which is close to the seepage results of the smooth and parallel plate model.

Although the difference between the forward and reverse seepages cannot be clearly demonstrated in Figure 4, the relationship between relative effective aperture $\left(e_{h} / e_{m}\right)_{C}$ and the Reynolds number in two directions under the same Reynolds number can be obtained through the difference between the values of $e_{h} / e_{m}$ in two directions. As is shown in Figure 5, when the Reynolds number varies from 0.001 to 10, the value of $\left(e_{h} / e_{m}\right)_{C}$ is basically zero, suggesting that the seepage property of the fracture is only related to the geometry of the fracture in the laminar (linear) flow, no matter how the roughness of the fracture changes. Besides, the flow direction of the fluid in the fracture will not make a difference in the seepage characteristics. When $\operatorname{Re}>10$, the fluid state of the fluid in the fracture enters the nonlinear stage, and the values of $\left(e_{h} / e_{m}\right)_{C}$ of the approximate models of decomposition levels $\sim 4$ are not zero and increase with the increase of the Reynolds number. Meanwhile, the values of $\left(e_{h} / e_{m}\right)_{C}$ of the approximate models of decomposition levels $5 \sim 8$ are almost zero and do not change with the Reynolds number. In conclusion, the existence of nonlinear seepage does not necessarily result in the discrepancy between the two directions' hydraulic characteristics. However, the discrepancy between the hydraulic characteristics of the two directions must be due to nonlinear seepage.

4.2. Evolution of Non-Darcy Coefficient. It can be seen from Section 4.1 that as the Reynolds number increases, the relationship between the flow rate $Q$ and the pressure gradient 


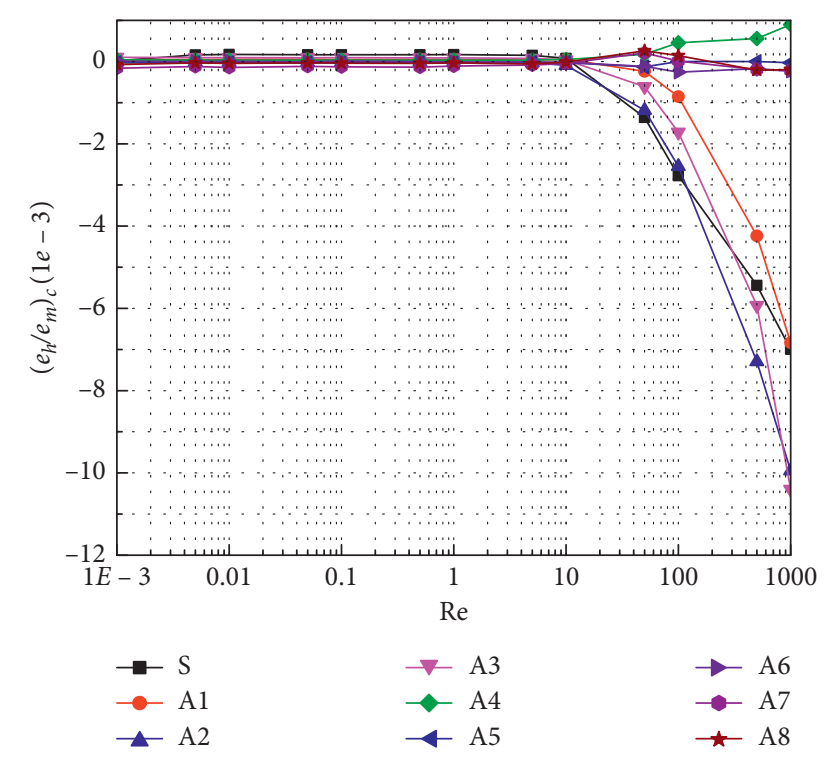

FIGURE 5: Variation of the difference of relative hydraulic aperture $\left(e_{h} / e_{m}\right)_{C}$ with Reynolds number under different decomposition levels in the approximate profile models.

$\nabla P$ is no longer linear, and equation (5) is not applicable. In describing the nonlinear relationship between pressure gradient and flow rate, the Forchheimer equation [50] is the most widely accepted:

$$
-\nabla P=A Q+B Q^{2}
$$

where $A$ and $B$ are the coefficients of the linear and nonlinear terms. Cao et al. [11] pointed out that the nonlinearity of fluid flow caused by inertia force had a remarkable influence on hydraulic behavior with high hydraulic pressure. When the Reynolds number is small, the inertia effect can be neglected (the nonlinear term $B Q^{2}$ can be neglected). In this case, equation (6) evolves into equation (5). From the changing trend of $\left(e_{h} / e_{m}\right)$ with the Reynolds number, it is appropriate to adopt equation (6) to describe the relationship between pressure gradient $\nabla P$ and flow rate $Q$. So we add Reynolds numbers of 300 and 750 among $10,50,100,500$, and 1000 to increase the accuracy of the fitted coefficients $A$ and $B$. It can be drawn from Figure 6 that the Forchheimer equation can well reflect the nonlinear relationship between $\nabla P$ and $Q$. The seepage coefficients in the forward direction $\left(A_{+}, B_{+}\right)$and reverse direction $\left(A_{-}, B_{-}\right)$under different decomposition levels and their regression coefficients are listed in Table 1 . As is shown in Figure 6, with the increase of decomposition level, the nonlinear characteristic between $\nabla P$ and $Q$ gradually weakens and finally tends to be stable. The pressure gradient $\nabla P$ is obviously different in two directions when the original profile model to the third approximate profile model shares the same flow rate boundary, while $\nabla P$ in two directions in the 4 th $\sim 8$ th approximate profile models are basically the same.

For single fractures, the coefficients can be obtained by the two following equations $[51,52]$ :

$$
\begin{aligned}
& A=\frac{\mu}{k A_{h}}=\frac{12 \mu}{w e_{h}^{3}}, \\
& B=\frac{\beta \rho}{A_{h}^{2}}=\frac{\beta \rho}{w^{2} e_{h}^{2}},
\end{aligned}
$$

where $k$ is the hydraulic conductivity of rock fracture, $\beta$ is the non-Darcy coefficient, and $A_{h}$ is the area of equivalent cross section. The linear term coefficient $A$ represents the fracture's inherent permeability, which is only related to the equivalent hydraulic aperture $e_{h}$. It is clearly shown in Figure 5 that the equivalent hydraulic aperture of the forward and reverse directions is almost the same in the Darcy flow state. Therefore, the coefficients of $A$ in two directions should also be the same. Although there are differences between $A_{+}$and $A_{-}$, which are fitted by equation (6), the primary source of nonlinear seepage comes from the nonlinear term. The difference of seepage in two directions is also derived from the nonlinear term. Therefore, the difference of coefficient $A$ is not discussed and studied here; coefficient $B$ is mainly focused instead, as opposed to porous media where both coefficients $A$ and $B$ should be simultaneously parameterized $[51,53]$. The difference between forward and reverse seepages can only result from the nonDarcy coefficient $\beta$, so the non-Darcy coefficient $\beta$ can be used to quantitatively characterize the discrepancy of seepage in two directions in the rough fracture. According to the fitted $B_{+}$and $B_{-}$, the non-Darcy coefficients $\beta_{+}$and $\beta_{-}$, which are the non-Darcy coefficients in two directions, can be calculated, respectively, by equation (7b). The results can be found in Table 1 .

The variation of the non-Darcy coefficients $\beta_{+}$and $\beta_{-}$ with the decomposition level is plotted in Figure $7(\mathrm{a})$. As the decomposition level increases, $\beta_{+}$and $\beta_{-}$decrease gradually first and then tend to be stable when the decomposition level is over 4 . The non-Darcy coefficient $\beta_{+}$is significantly larger than $\beta_{-}$when the decomposition level is from 0 to $3 . \beta_{C}$ is defined as the difference between $\beta_{+}$and $\beta_{-}$, and the variation of $\beta_{C}$ with decomposition level is plotted in Figure $7(\mathrm{~b})$. With the increase of the decomposition level, $\beta_{C}$ is slightly decreased. $\beta_{C}$ of decomposition levels 4 and $5 \sim 8$ are -0.43 and almost zero, respectively, while that of decomposition levels $1 \sim 3$ is over 10 , suggesting that the seepage direction no longer affects the fracture's hydraulic characteristics in the 4 th approximate profile (primary roughness) models, and the secondary roughness may be the geometric basis for the difference between seepages in two directions.

\section{Mechanism of the Discrepancy between the Forward and Reverse Seepages}

5.1. Discrepancy in Eddy Currents between Seepages in Two Directions. In this paper, the mechanical aperture is only $0.5 \mathrm{~mm}$, while the model is $100 \mathrm{~mm}$ long, which results in the large aspect ratio of the overall model. Therefore, the eddy current distribution characteristics of the entire model cannot be displayed well. A local representative area is taken 


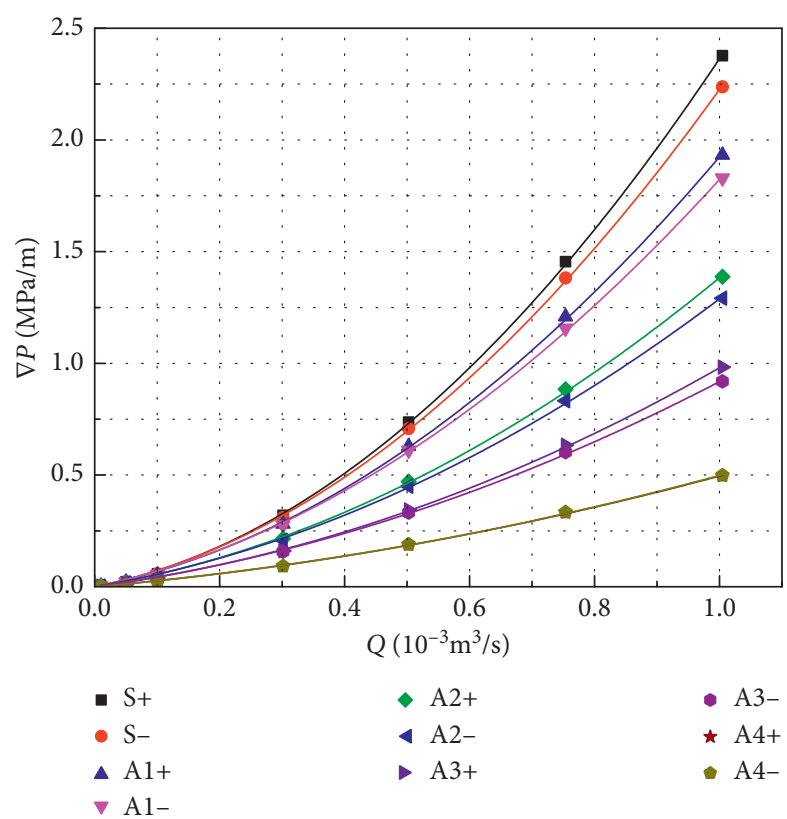

(a)

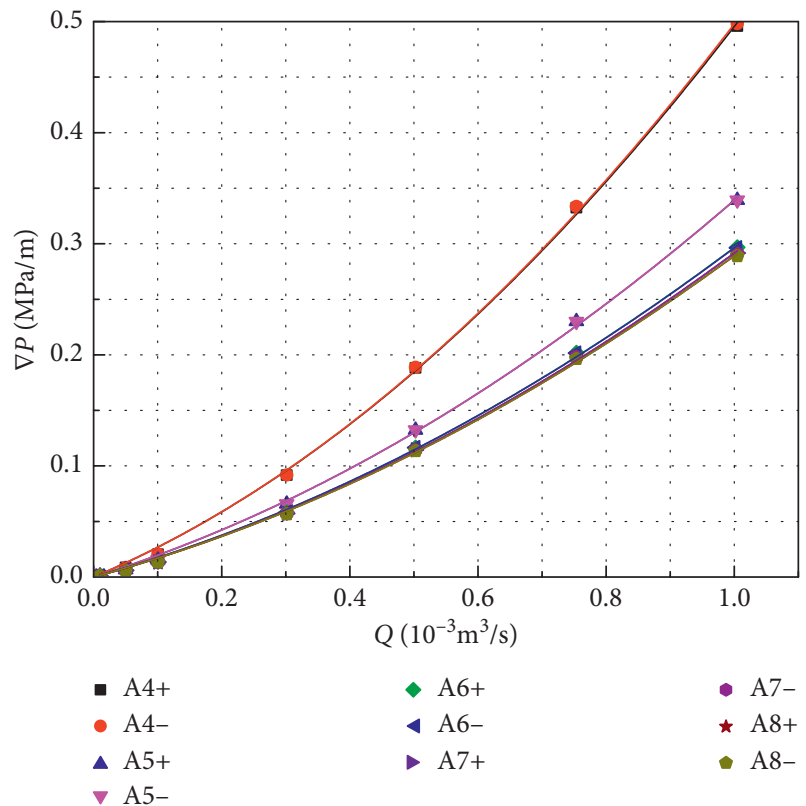

(b)

FIgURe 6: Analysis of nonlinear seepage results.

TABLE 1: Statistical table of non-Darcy fitted parameters at different scales.

\begin{tabular}{|c|c|c|c|c|c|c|c|c|}
\hline & $\begin{array}{c}A_{+} \\
\left(\times 10^{9} \mathrm{~kg} \cdot \mathrm{s}^{-1} \cdot \mathrm{m}^{-5}\right) \\
\end{array}$ & $\begin{array}{c}B_{+} \\
\left(\times 10^{12} \mathrm{~kg} \cdot \mathrm{m}^{-8}\right)\end{array}$ & $R^{2}$ & $\begin{array}{c}\beta_{+} \\
\left(\mathrm{m}^{-1}\right)\end{array}$ & $\begin{array}{c}A_{-} \\
\left(\times 10^{9} \mathrm{~kg} \cdot \mathrm{s}^{-1} \cdot \mathrm{m}^{-5}\right)\end{array}$ & $\begin{array}{c}B_{-} \\
\left(\times 10^{12} \mathrm{~kg} \cdot \mathrm{m}^{-8}\right)\end{array}$ & $R^{2}$ & $\begin{array}{c}\beta_{-} \\
\left(\mathrm{m}^{-1}\right)\end{array}$ \\
\hline$S$ & 0.539 & 1.825 & 0.9999 & 201.889 & 0.559 & 1.668 & 0.9999 & 184.502 \\
\hline $\mathrm{A} 1$ & 0.550 & 1.374 & 0.9998 & 155.908 & 0.576 & 1.247 & 0.9998 & 141.403 \\
\hline $\mathrm{A} 2$ & 0.466 & 0.917 & 0.9997 & 119.003 & 0.476 & 0.813 & 0.9997 & 105.455 \\
\hline A3 & 0.369 & 0.611 & 0.9997 & 91.169 & 0.384 & 0.534 & 0.9996 & 79.607 \\
\hline A4 & 0.243 & 0.253 & 0.9995 & 49.133 & 0.242 & 0.256 & 0.9996 & 49.628 \\
\hline A5 & 0.180 & 0.159 & 0.9996 & 36.260 & 0.180 & 0.159 & 0.9996 & 36.244 \\
\hline A6 & 0.161 & 0.136 & 0.9996 & 33.387 & 0.161 & 0.136 & 0.9996 & 33.313 \\
\hline A7 & 0.158 & 0.134 & 0.9996 & 33.266 & 0.158 & 0.134 & 0.9996 & 33.214 \\
\hline A8 & 0.157 & 0.133 & 0.9996 & 33.110 & 0.157 & 0.132 & 0.9996 & 33.075 \\
\hline
\end{tabular}

out in this section to study the influence of flow direction on the seepage field, revealing the discrepancy between the forward and reverse seepages. The $X$-direction velocity contour and flow line distribution in the range of $X=$ [51 $\mathrm{mm}, 53 \mathrm{~mm}$ ] of the original model are selected, and the results of forward and reverse seepage are shown in Figure 8 when the Reynolds number is at $1,10,100$, and 1000, respectively. When $\operatorname{Re}>10$ and only the forward (or reverse) seepage direction is analyzed, as the Reynolds number increases, the eddy currents are about to emerge and are gradually enlarged at the location where the profile fluctuates, which is consistent with the observations of Lee et al. [8] and Lee et al. [37] using the micro-PIV (micro particle image velocity) system in the laboratory. Zou et al. [27] and Briggs et al. [45] also obtained similar conclusions through numerical simulation. When $\operatorname{Re}=1$ and 10 , the seepage in two directions was analyzed. There is no eddy current, and the distribution of velocity is the same, except that the velocity direction of the forward seepage is opposite to that of the reverse seepage. When $\operatorname{Re}=100$, there are eddy currents with different shapes and sizes in the forward and reverse seepage. The eddy current can be regarded as a "circulation zone" or "dead water zone," which will reduce the flow channel inevitably. As the eddy current's locations and sizes vary in two directions, the flow line and the velocity contour in two directions differ. When $\mathrm{Re}=1000$, the eddy zone becomes larger compared with that under $\operatorname{Re}=100$. Furthermore, where there is no eddy zone at $\mathrm{Re}=100$, a new eddy zone is created at $\mathrm{Re}=1000$. The expansion of the original eddy zone and the creation of a new eddy zone further compress the effective seepage channel. This has also led to a further increase in nonlinear seepage. Due to the inconsistent distribution of eddy zones, the difference between forward and reverse seepages has also increased. Cao et al. [11] pointed out that the discrepancy and $e_{m} / e_{h}$ ratio were influenced by recirculation zones, infilling materials, 


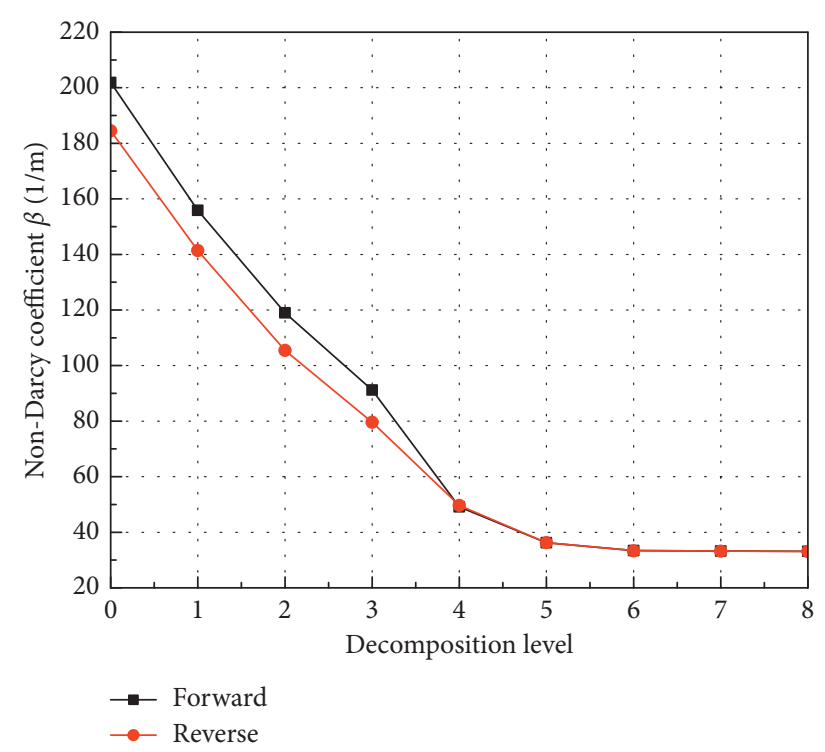

(a)

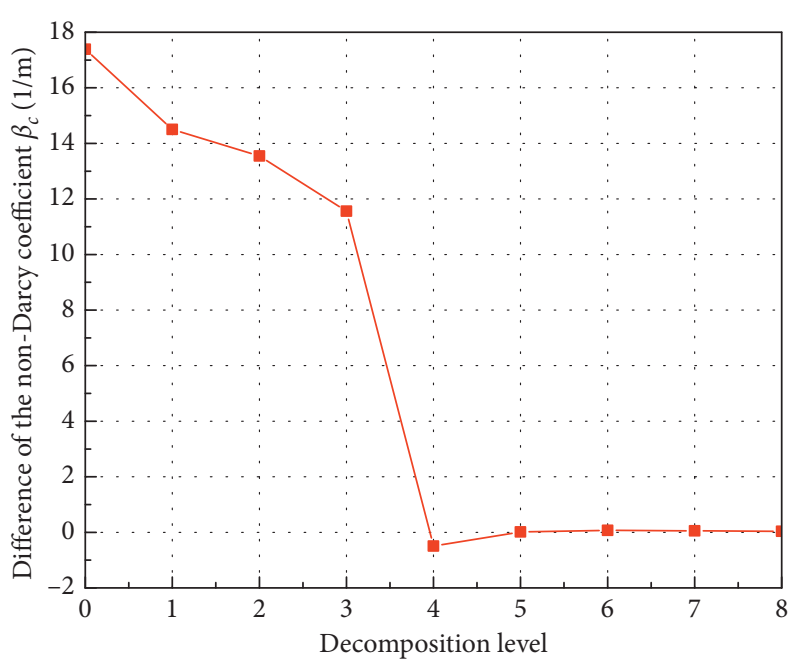

(b)

Figure 7: The correlation between Non-Darcy coefficients $\beta$ in the forward and reverse directions with the decomposition level: (a) nonDarcy coefficient $\beta$; (b) difference of the non-Darcy coefficient $\beta_{C}$.

roughness, contact areas, and inertia force. A two-dimensional numerical model showed that the vortices were the important cause of damage to the radiation flow [54].

In conclusion, the "dead water zone" generated by the eddy current significantly reduces the flow channel, which makes the effective flow channel narrow and then makes the distribution of the velocity and flow line of the $X$-direction more complex. So, the eddy current's existence has a decisive effect on the existence and development of nonlinear seepage $[27,28,45]$. The difference between the eddy current distribution shapes and locations in two directions is the main reason for the discrepancy between the nonlinear seepages in two directions. The eddy current's location and region are related to the direction of the seepage and the Reynolds number. With the increase of the Reynolds number, the eddy current region becomes larger, and even new eddy currents are generated. It is indicated that the difference between non-Darcy seepages in two directions will be enlarged with the increase of the number.

\subsection{Effect of the Detailed Profile on Eddy Current Generated by} Seepage in Two Directions. To further study the non-Darcy seepage characteristics of two directions in the approximate profile model at different decomposition levels, the velocity and flow line distribution in the local region of $X=[51 \mathrm{~mm}$, $53 \mathrm{~mm}$ ], as shown in Figure 9, is selected. When only the forward (reverse) seepage is analyzed, with the increase of the decomposition level, the region of the eddy current is gradually narrowed [26] compared with the original profile model (Figure 8(d)). At the fourth decomposition level, there is not any eddy. Therefore, the secondary roughness plays a leading role in the generation of the eddy current, which is following the results of Zou et al. [27], Wang et al. [28], and Dou et al. [7]. When the forward and reverse seepage fields are compared and analyzed, with the increase of the decomposition level, the eddy current regions are both narrowed, and the flow line is parallel to the fracture profile. At the 8th decomposition level, the velocity contour and flow line are similar to those of the smooth and parallel plate models. Therefore, with the increase of the decomposition level, the eddy current shape and region decrease and disappear at last in two directions, resulting in the decrease of the discrepancy between non-Darcy seepages in two directions. Moreover, this discrepancy will vanish when the eddy current disappears.

In summary, as the decomposition level increases, the detailed information of the fracture profile containing is less, resulting in the shape and region of the eddy current decreasing or even disappearing. It is revealed that the detailed profile is decisive in the generation and development of the eddy current. From the results of the 1 4th decomposition levels, it can be seen that the local concave and convex area generated by the detailed profile in the fracture provides a potential place for the generation of eddy current in the nonlinear seepage. Simultaneously, with the decrease of the range of the eddy current, the difference between non-Darcy seepages in two directions decreases, which further indicates that the discrepancy between the eddy currents in two directions is the primary cause of the discrepancy between non-Darcy seepages in two directions. Besides, the secondary roughness $(D 1+\mathrm{D} 2+D 3+\mathrm{D} 4)$ is related to the existence and development of eddy currents. Therefore, it can be concluded that the secondary roughness is the geometric basis for the discrepancy between non-Darcy seepages in two directions. 

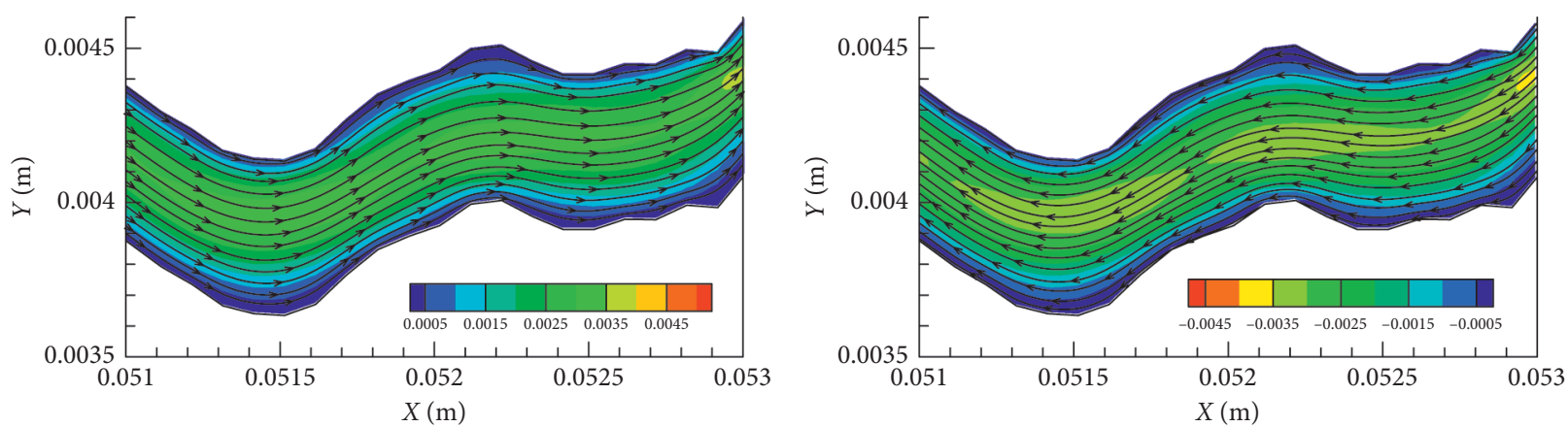

(a)
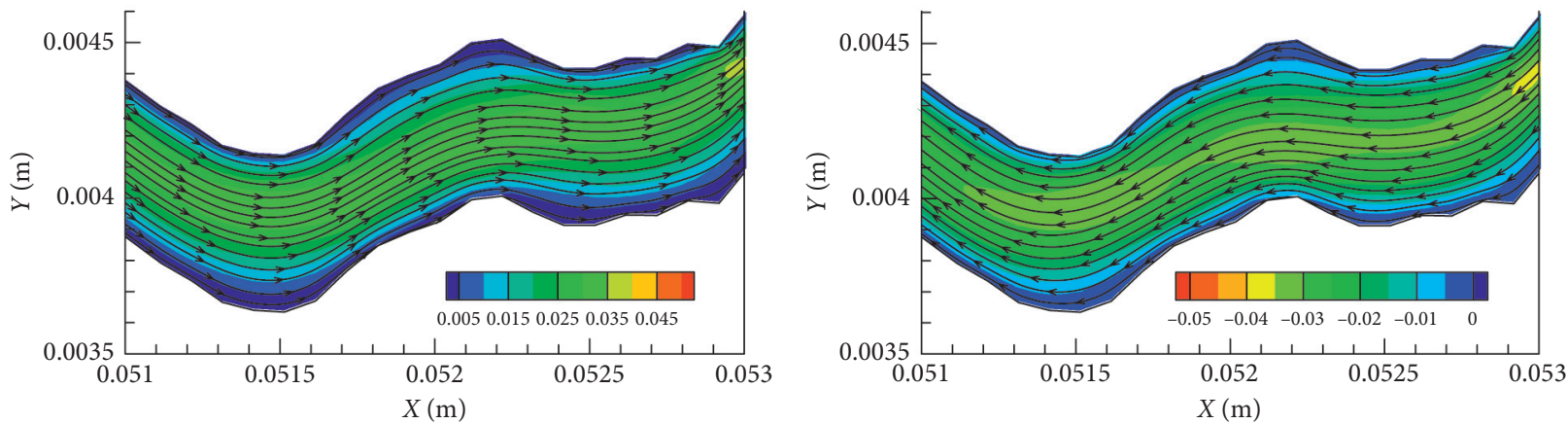

(b)
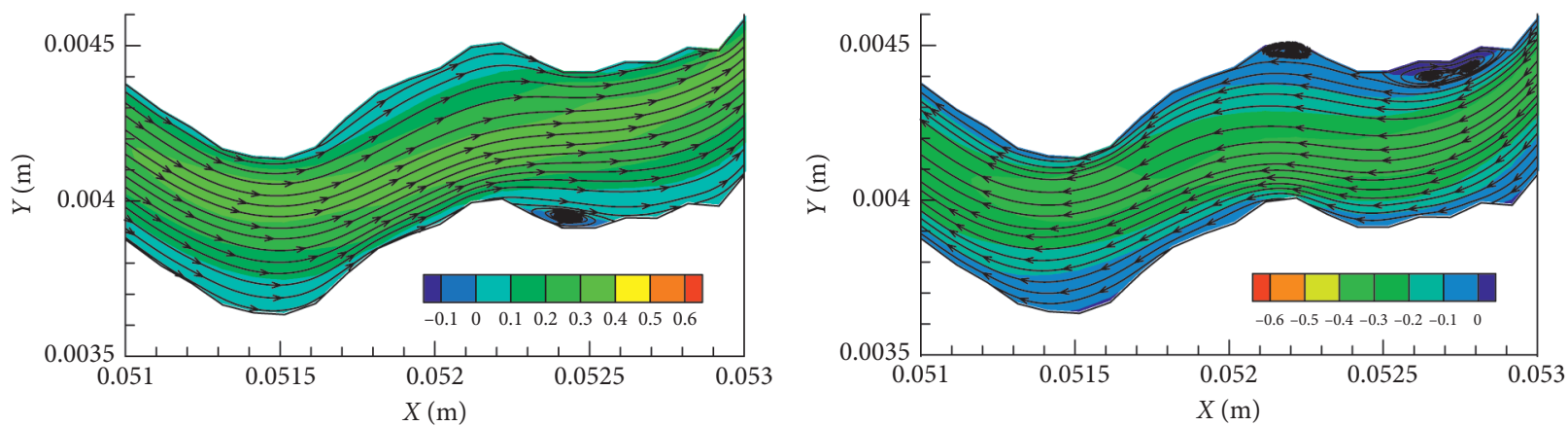

(c)
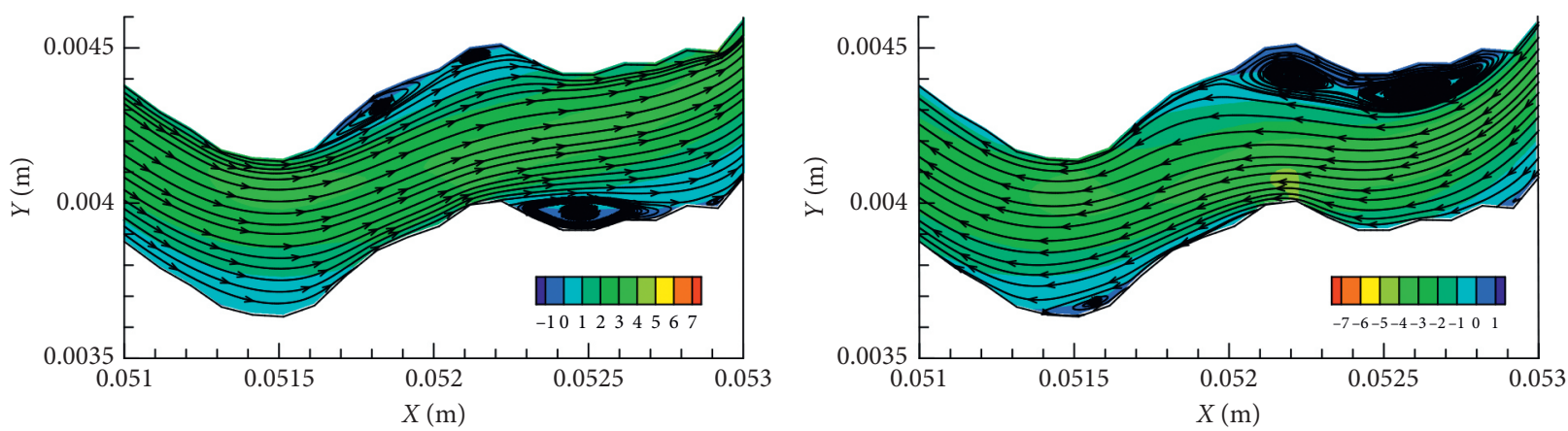

(d)

FiguRE 8: $X$-direction velocity contour and flow line of the original profile model under different Reynolds numbers in the forward and reverse directions (the contour represents the velocity distribution, $m / s$ ). (a) $\operatorname{Re}=1$. (b) $\operatorname{Re}=10$. (c) $\operatorname{Re}=100 .(\mathrm{d}) \mathrm{Re}=1000$.

\section{Discussion}

6.1. Directional Roughness and Non-Darcy Coefficient. We know that when a rock sample with a single rough fracture is subjected to a forward and reverse shear experiment, the forward and reverse shear strength is inconsistent, and this is related to the inconsistency of the forward and reverse roughness. Zhang et al. [55] pointed out that surface roughness plays a significant role in affecting fracture flow in the review paper. Hence, it is necessary to consider the effect 

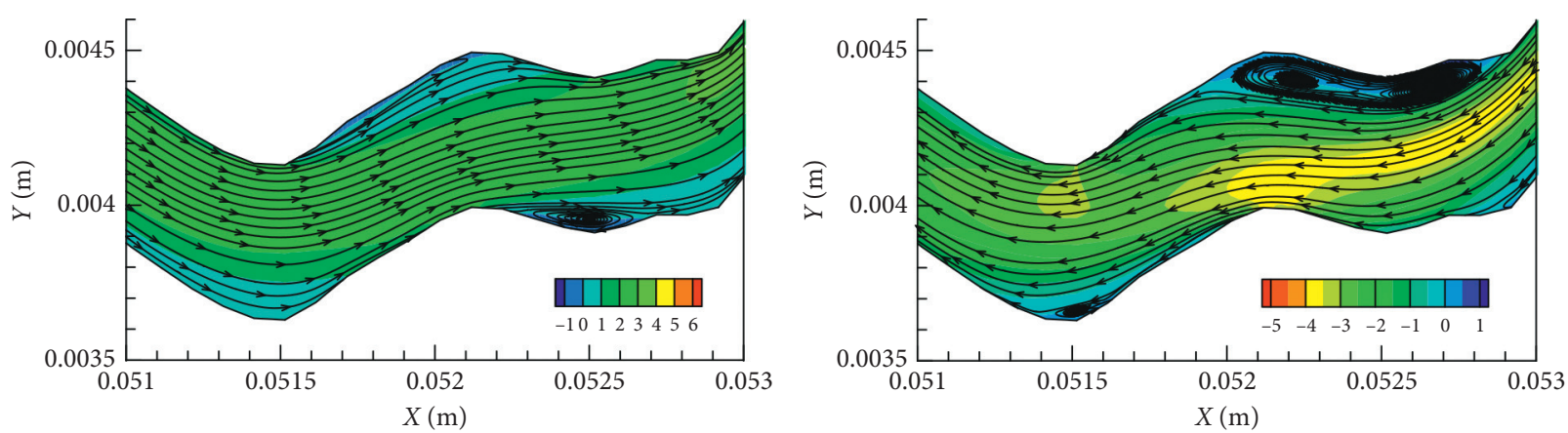

(a)
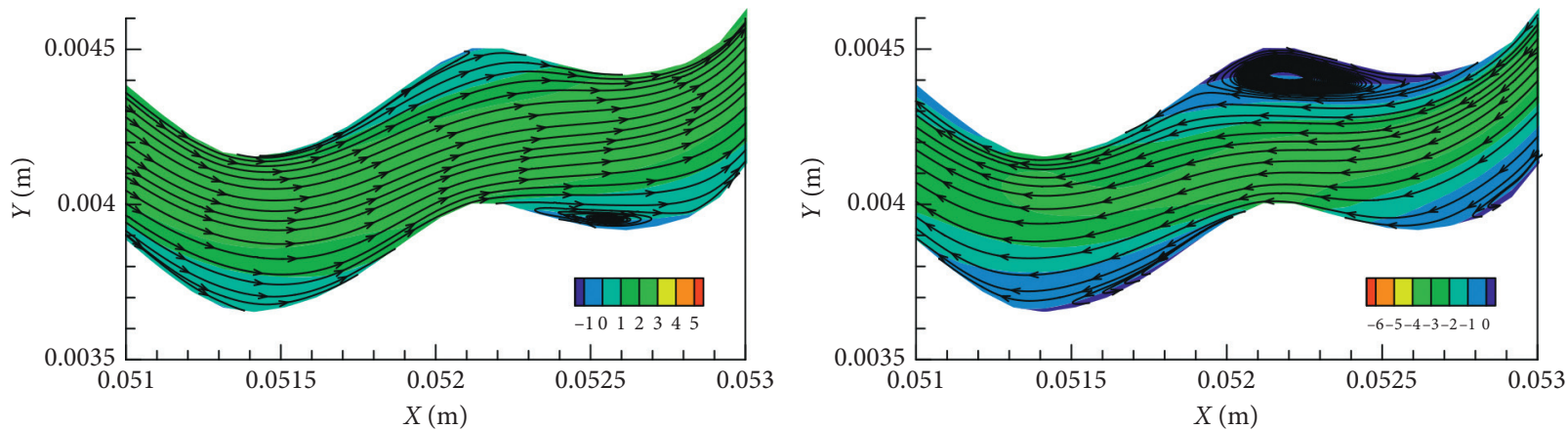

(b)
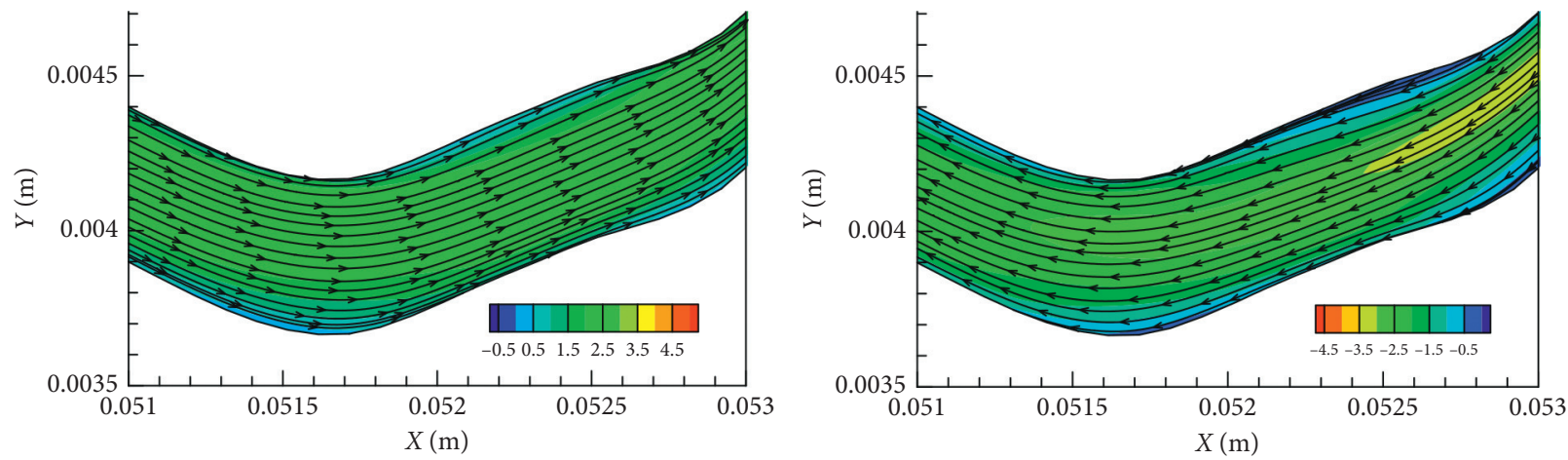

(c)
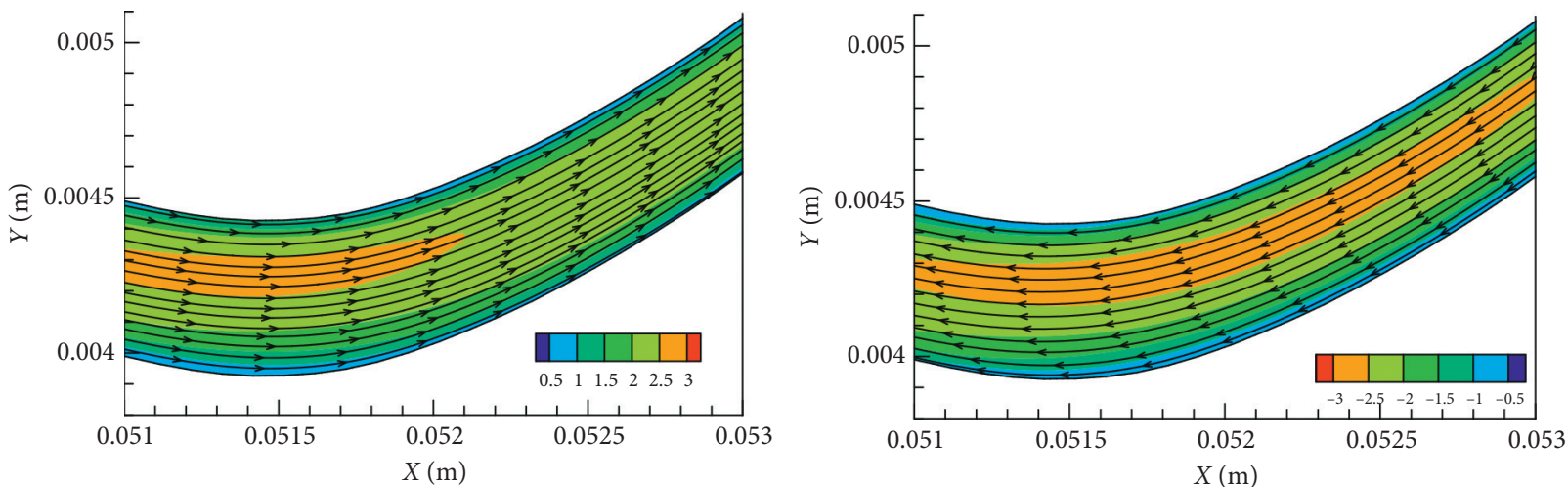

(d)

Figure 9: Continued. 

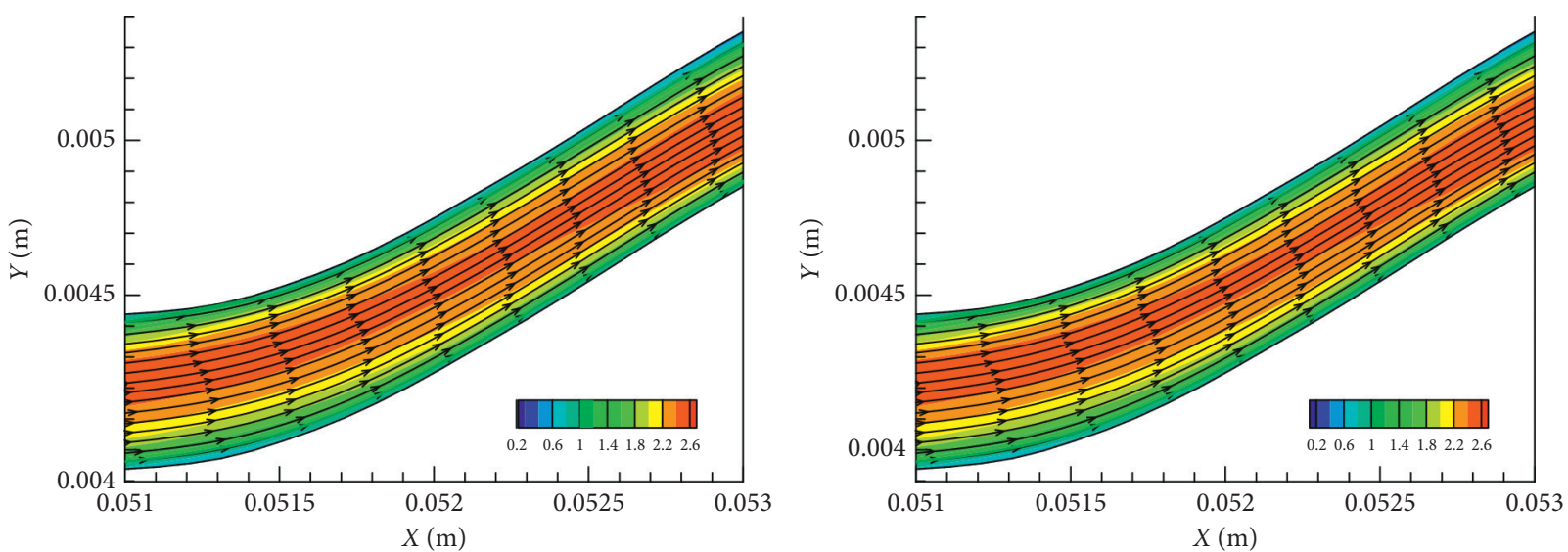

(e)
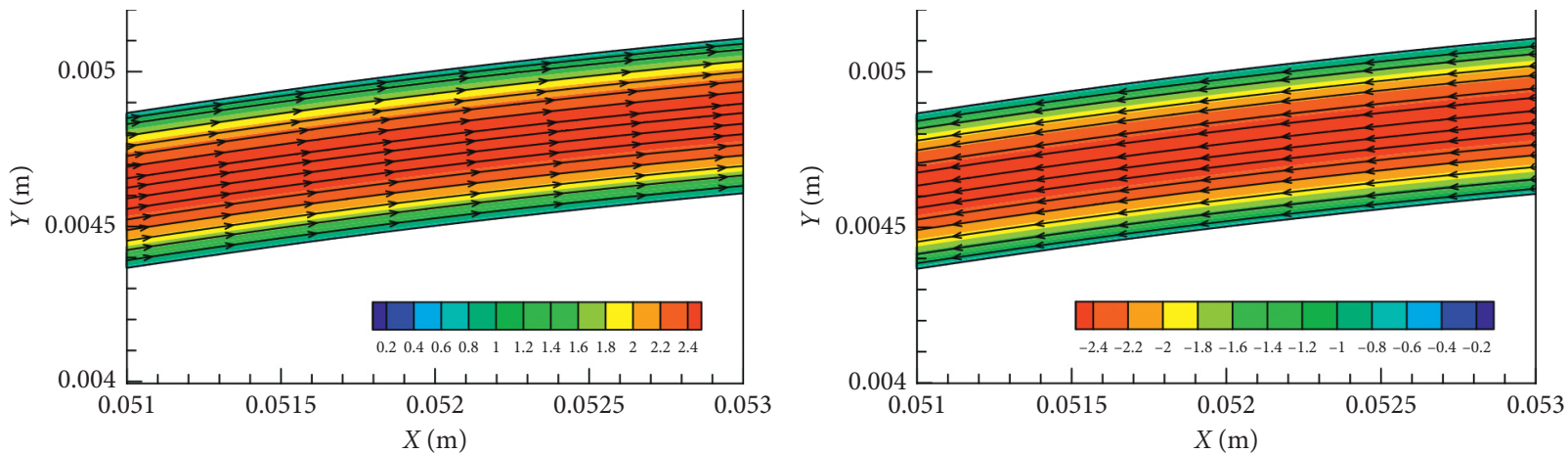

(f)
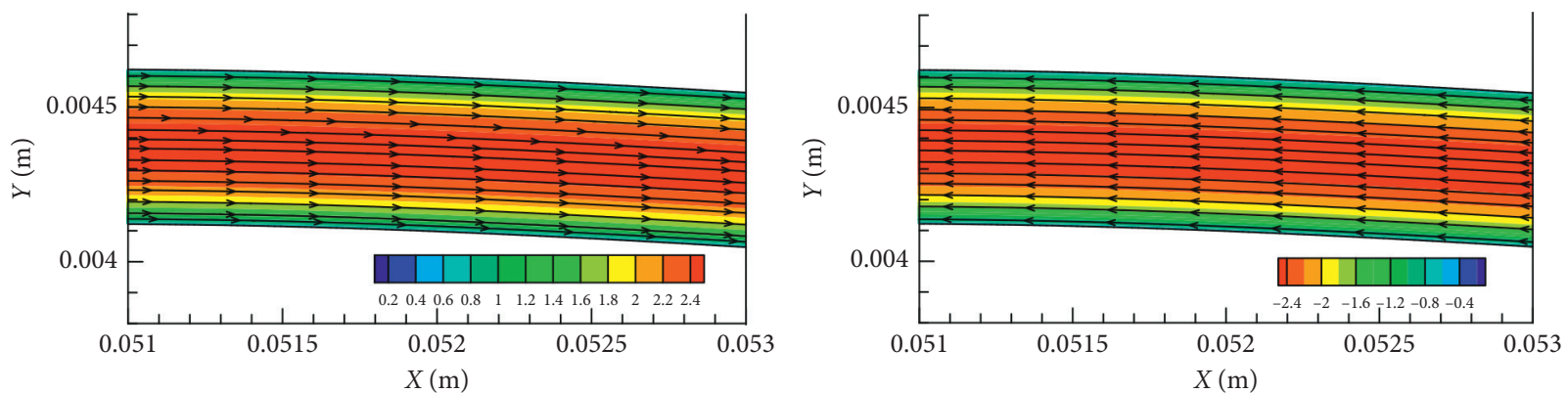

(g)
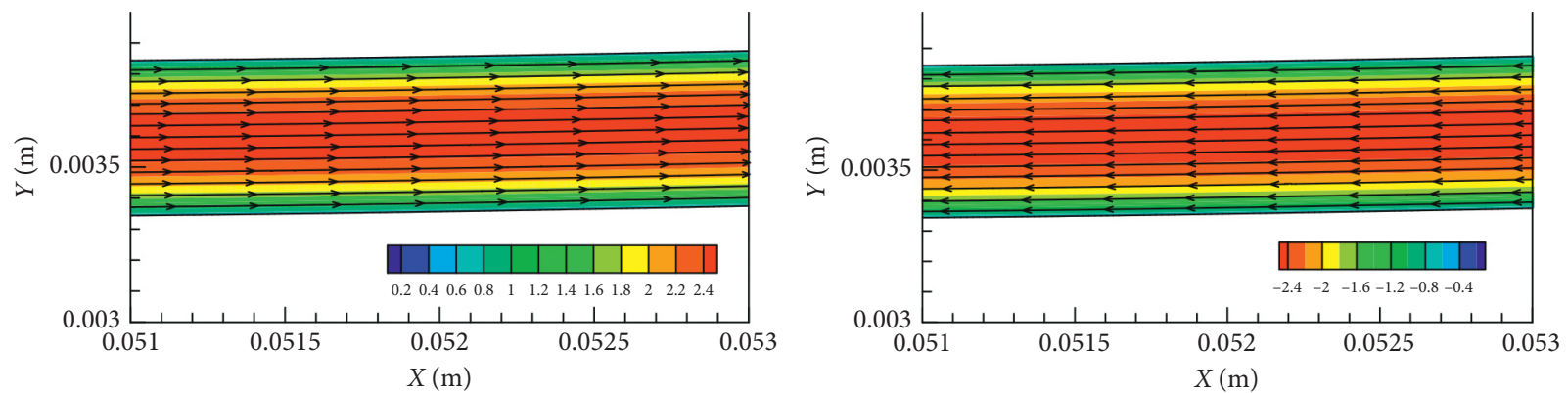

(h)

Figure 9: $X$-direction velocity and flow line of two directions in the approximate models when $\operatorname{Re}=1000$ (the contour represents the velocity distribution, m/s). (a) Level 1. (b) Level 2. (c) Level 3. (d) Level 4. (e) Level 5. (f) Level 6. (g) Level 7. (h) Level 8.

of surface morphology or roughness on fluid flow, which can uncover underlying flow mechanisms inside fractures and advance our understanding of the fracture flow.
It can be seen from the previous chapter that, in the nonlinear seepage stage, the forward and reverse seepage characteristics are inconsistent, and whether this is related to 


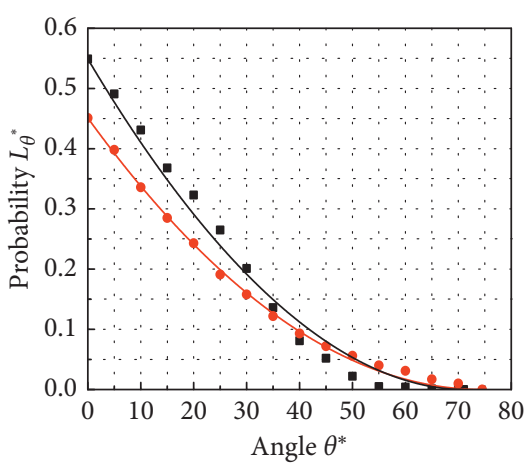

- S-

- S+

(a)

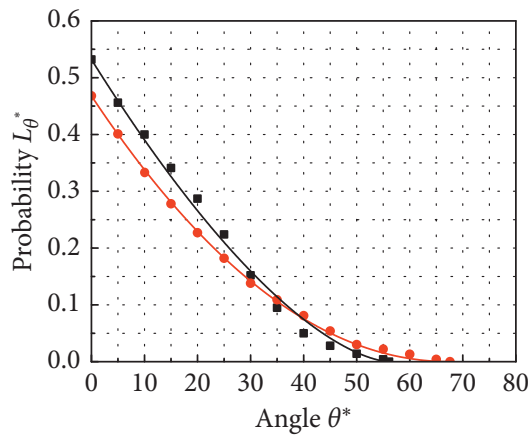

- A3-

- $\mathrm{A} 3+$

(d)

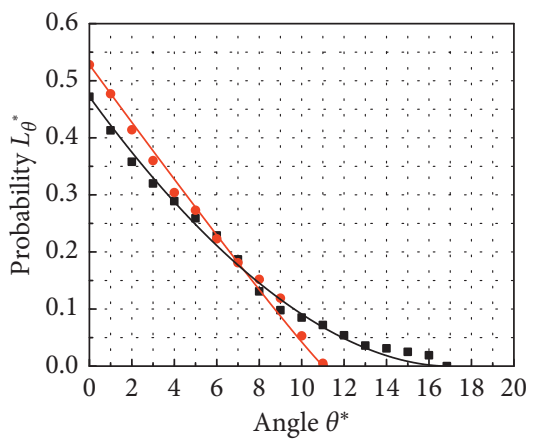

- A6-

- A6+

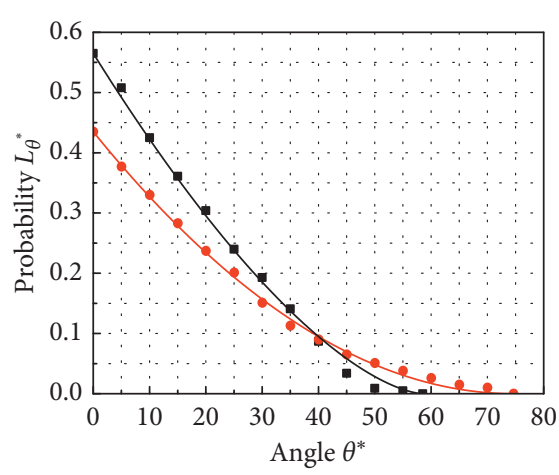

- A1-

- $\mathrm{A} 1+$

(b)

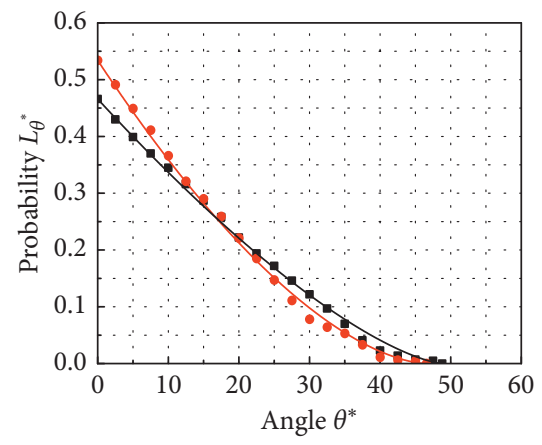

- A4-

- A4+

(e)

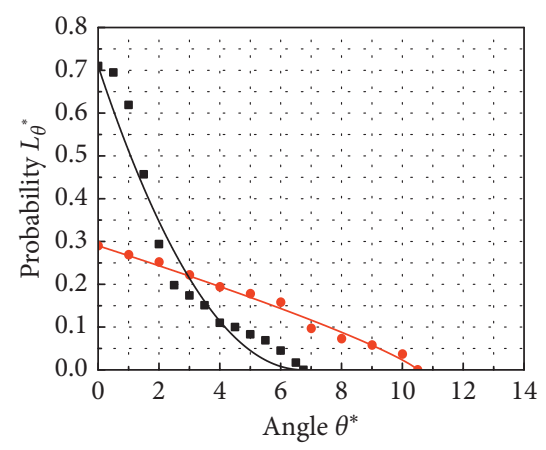

- A7-

- A7+

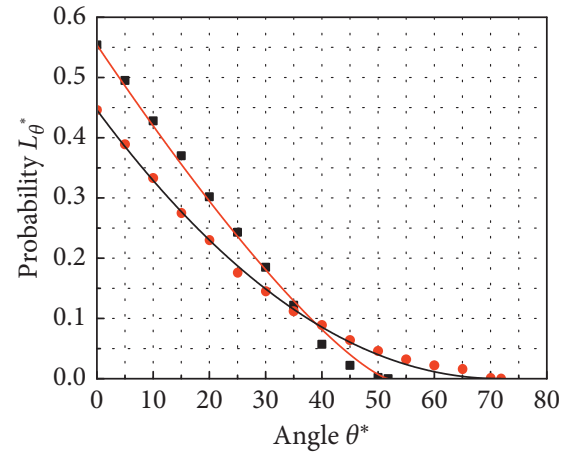

- A2-

- $\mathrm{A} 2+$

(c)

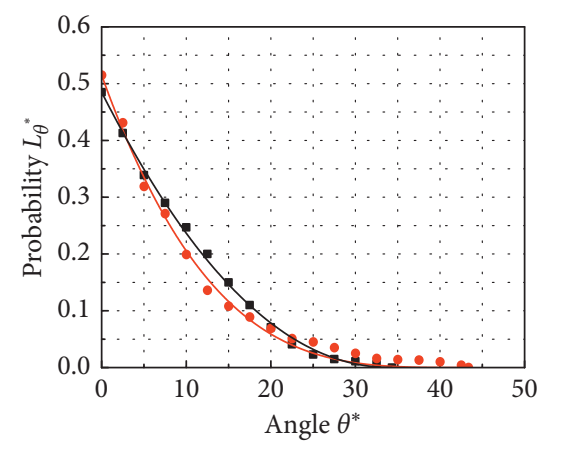

- A5-

- A5+

(f)

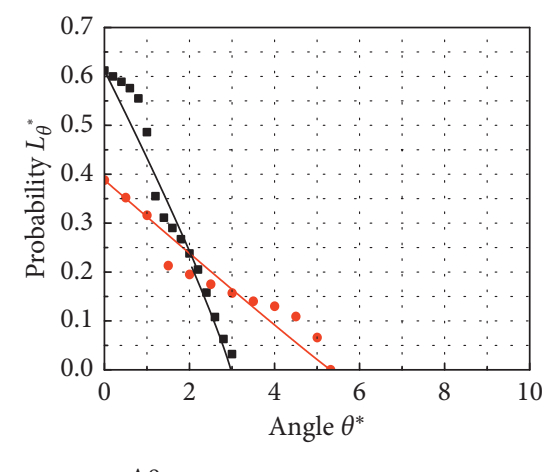

- A8-

- A8+

(i)

FIGURE 10: Angle probability distribution and fitting curve of rough fracture profile under different decomposition levels. (a) Original. (b) Level 1. (c) Level 2. (d) Level 3. (e) Level 4. (f) Level 5. (g) Level 6. (h) Level 7. (i) Level 8.

the forward and reverse roughness will be briefly discussed in this section. Belem et al. [56], Zhang et al. [57], Grasselli et al. [58], Grasselli [59], and Tatone and Grasselli [60] have proposed methods and formulas for describing directional roughness. In this paper, the directional roughness presented by Tatone and Grasselli [60] is selected as an index to measure the inconsistency of forward and reverse roughness.

Grasselli et al. [58] proposed a method and parameter for calculating directional surface roughness based on the $3 \mathrm{D}$ scanning point cloud. Tatone and Grasselli [60] based on the method of Grasselli et al. [58] proposed the directional roughness measurement of $2 \mathrm{D}$ fracture profile. The method used to calculate the roughness of the $2 \mathrm{D}$ fracture profile direction is as follows: 1 . Use the least-squares method to establish the best-fitting line and set it as the $X$-axis. 2 . Connect adjacent points to form a series of short straight line segments. 3. Select the analysis direction and calculate each line segment's inclination angle. For the 2D fracture profile, only two shear directions (forward and reverse) need to be considered. A length score $L_{\theta^{*}}$ that is steeper than the 
TABLe 2: Statistical table of relevant parameters of direction roughness $L_{0} \theta_{\max }^{*} /(C+1)$ under different decomposition levels.

\begin{tabular}{|c|c|c|c|c|c|c|c|c|c|c|}
\hline & \multicolumn{4}{|c|}{ Forward } & \multicolumn{4}{|c|}{ Reverse } & \multicolumn{2}{|c|}{$L_{0} \theta_{\max }^{*} /(C+1)\left({ }^{\circ}\right)$} \\
\hline & $L_{0}$ & $\theta_{\max }^{*}$ & C & $R^{2}$ & $L_{0}$ & $\theta_{\max }^{*}$ & C & $R^{2}$ & Forward & Reverse \\
\hline$S$ & 0.451 & 74.506 & 1.949 & 0.998 & 0.549 & 71.028 & 1.933 & 0.988 & 11.396 & 13.297 \\
\hline A1 & 0.435 & 74.628 & 1.953 & 0.998 & 0.565 & 58.505 & 1.549 & 0.997 & 10.995 & 12.970 \\
\hline A2 & 0.446 & 71.846 & 1.976 & 0.998 & 0.554 & 51.793 & 1.296 & 0.997 & 10.768 & 12.496 \\
\hline A3 & 0.468 & 67.592 & 1.991 & 0.999 & 0.532 & 56.096 & 1.584 & 0.995 & 10.575 & 11.547 \\
\hline A4 & 0.534 & 46.559 & 1.631 & 0.998 & 0.466 & 48.809 & 1.425 & 0.997 & 9.449 & 9.379 \\
\hline A5 & 0.515 & 43.363 & 3.233 & 0.993 & 0.485 & 34.327 & 2.086 & 0.998 & 5.276 & 5.395 \\
\hline A6 & 0.528 & 11.021 & 1.033 & 0.993 & 0.472 & 16.843 & 1.784 & 0.994 & 2.863 & 2.855 \\
\hline A7 & 0.290 & 10.500 & 0.797 & 0.988 & 0.710 & 6.750 & 1.776 & 0.958 & 1.695 & 1.726 \\
\hline A8 & 0.388 & 5.318 & 0.972 & 0.912 & 0.612 & 3.061 & 0.771 & 0.968 & 1.046 & 1.058 \\
\hline
\end{tabular}

gradually higher angle threshold $\theta^{*}$ can be obtained based on each line segment's inclination angle. The relationship between the two can be fitted by equation (8). The detailed theory and method can be found in the paper by Tatone and Grasselli [60]:

$$
L_{\theta^{*}}=L_{0}\left(\frac{\theta_{\max }^{*}-\theta^{*}}{\theta_{\max }^{*}}\right)^{C}
$$

where $L_{0}$ is the length ratio where the angle threshold is $0^{\circ}$, $\theta_{\max }^{*}$ represents the maximum apparent inclination in the analysis direction, and $C$ is a dimensionless fitting parameter, which characterizes the distribution's shape. By integrating the area under the curve between $L_{\theta^{*}}$ and the angle threshold $\theta^{*}$, the roughness $L_{0} \theta_{\text {max }}^{*} /(C+1)$ in the analysis direction can be obtained by the following equation:

$$
L_{0} \int_{0}^{\theta_{\max }^{*}}\left(\frac{\theta_{\max }^{*}-\theta^{*}}{\theta_{\max }^{*}}\right)^{C} \mathrm{~d} \theta^{*}=L_{0}\left(\frac{\theta_{\max }^{*}}{C+1}\right) .
$$

Figure 10 shows the forward and reverse $\theta^{*}$ and $L_{\theta^{*}}$ scatter points calculated by the Tatone and Grasselli [60] method of the original profile and 8 approximate profiles. The dimensionless parameter $C$ can be determined using equation (8) for the curve fitting of the scatter point. The forward and reverse $L_{0}$ and $\theta_{\max }^{*}$ can also be obtained through calculation and statistics, and then the directional roughness of the forward and reverse $L_{0} \theta_{\text {max }}^{*} /(C+1)$ can be determined and are listed in Table 2. Figures 11(a) and 11(b) are, respectively, plotted as curves of the calculated forward and reverse direction roughness $L_{0} \theta_{\max }^{*} /(C+1)$ and its difference value $\left(L_{0} \theta_{\text {max }}^{*} /(C+1)\right)_{C}$ with the decomposition level. Figure 11 shows that the overall forward roughness $L_{0} \theta_{\max }^{*} /(C+1)$ is smaller than the reverse roughness. As the number of decomposition levels increases, the difference between the forward roughness and reverse roughness $\left(L_{0} \theta_{\max }^{*} /(C+1)\right)_{C}$ decreases. When it is decomposed to the fourth level, the roughness in the forward and reverse directions have tended to zero, and the subsequent fifth to eighth levels also tend to zero. This is contrary to the nonDarcy coefficient $\beta_{C}$ curve with the decomposition levels in Figure 7(b). The difference of forward and reverse nonDarcy coefficients $\beta_{C}$ and the difference of directional roughness $\left(L_{0} \theta_{\max }^{*} /(C+1)\right)_{C}$ under different decomposition levels corresponded. Figure 12 shows a good negative linear relationship between the difference of directional roughness $\left(L_{0} \theta_{\max }^{*} /(C+1)\right)_{C}$ and the difference of non-Darcy coefficient $\beta_{C}$ between forward and reverse directions. It can be seen from this section that the difference of directional roughness between forward and reverse directions can reflect the difference between forward and reverse non-Darcy flows (the difference of non-Darcy coefficients). However, it should also be seen that there are few samples used in this article, and the exact quantitative relationship between the difference of directional roughness and the difference of non-Darcy flow needs further research.

6.2. Single Rough Fracture in Fracture Network. The single fracture is the basic unit of the fracture network, and the seepage characteristics of the single fracture will also affect the seepage characteristics of the fracture network. The research on the difference between the forward and reverse seepages in single rough fracture can lay the foundation for future research on the forward and reverse seepage characteristics of the rough fracture network. When it is considered that the single fractures in the fracture network obey the cubic law, the seepage characteristics of the fracture network can be described by the anisotropic Darcy's law, as shown in the following equation:

$$
u_{j}=-K_{j i} J_{i}
$$

where $u_{j}$ is the velocity in direction $j, J_{i}$ is the hydraulic gradient in direction $i$, and $K_{j i}$ is the equivalent permeability coefficient tensor. As shown in this paper's research results, in the case of Darcy seepage in rough single fractures, there is no difference in the seepage characteristics of the forward and reverse seepage directions, and both strictly obey the cubic law. In the Darcy seepage state, the permeability coefficient $\mathrm{K}$ of the fracture network composed of rough single fractures in the relative seepage direction (such as $0^{\circ}$ and $180^{\circ}, 90^{\circ}$ and $270^{\circ}$ ) is also consistent, which conforms to the characteristics of a tensor. Thus, the equivalent permeability coefficient tensor $K_{i j}$ can express the permeability characteristics of the seepage in the Darcy seepage state.

With the increase of hydraulic gradient, not only the single fracture but also the fracture network will enter nonDarcy seepage. For the fracture network, Liu et al. [42], Liu 


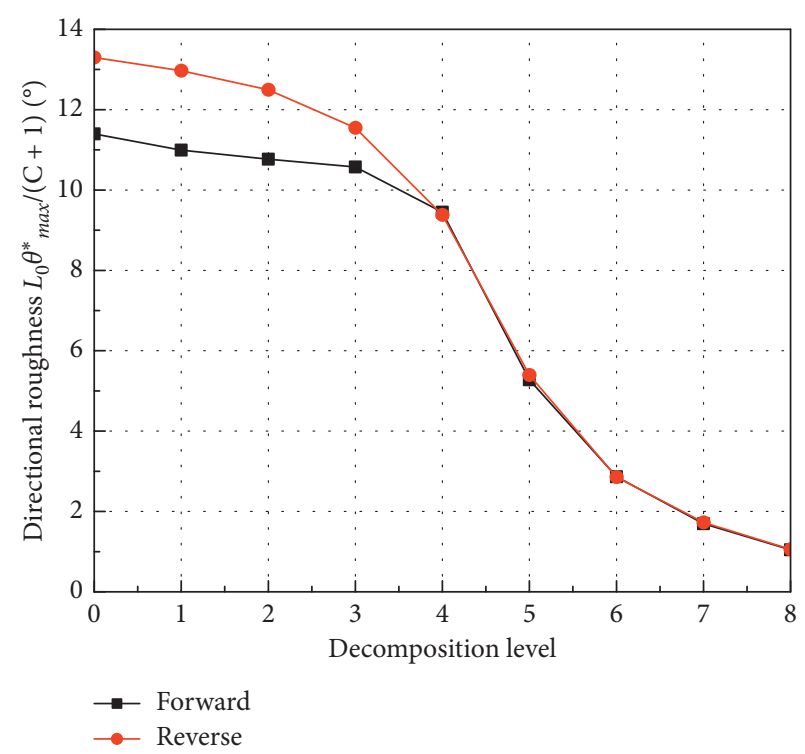

(a)

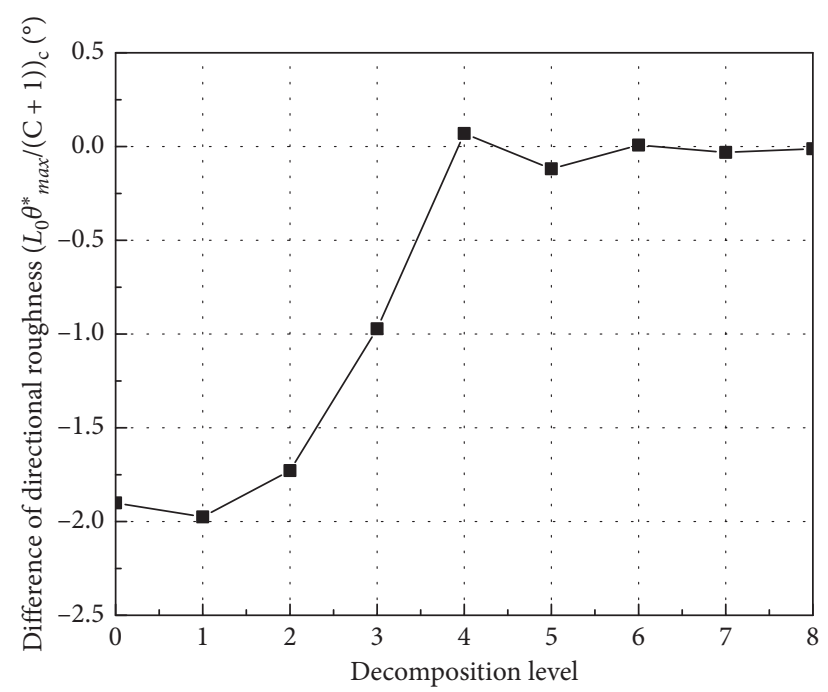

(b)

Figure 11: The relationship between the roughness in the forward and reverse directions (a) $L_{0} \theta_{\max }^{*} /(C+1)(\mathrm{b})$ and its difference $\left(L_{0} \theta_{\max }^{*} /(C+1)\right)_{C}$ with the decomposition level.

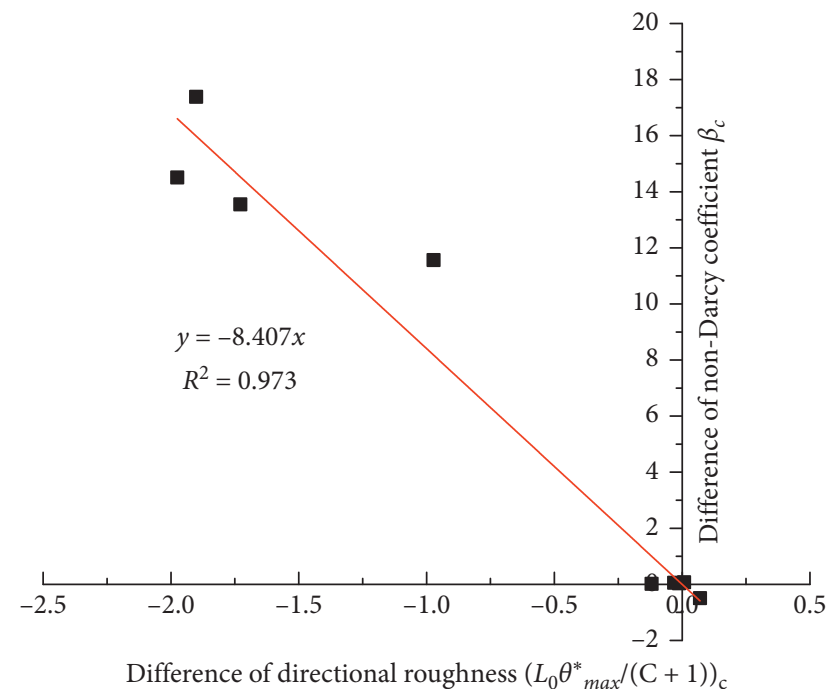

Figure 12: Relationship between the difference of non-Darcy coefficient $\beta_{C}$ and the difference of directional roughness $\left(L_{0} \theta_{\max }^{*} /(C+1)\right)_{C}$.

et al. [61], and Yin et al. [62] point out that when the hydraulic gradient is greater than a certain value, the ratio of flow velocity to hydraulic gradient is no longer constant, which no longer satisfies Darcy's law. The seepage flow in the fracture network will also enter the state of non-Darcy seepage. Similar to the use of Forchheimer law (equation (6)) to describe the non-Darcy flow in a single rough fracture, the non-Darcy flow in a fracture network is also described using the Forchheimer law (equation (11)) of anisotropic seepage [63]:

$$
-J_{i}=A_{i j} u_{j}+B_{i j}|\mathbf{u}| u_{j}=\frac{K_{i j}^{*}}{|\mathbf{K}|} u_{j}+\frac{\beta_{i j}}{g}|\mathbf{u}| u_{j} .
$$

In the equation, $A_{i j}$ and $B_{i j}$ are, respectively, the coefficient tensors of the viscous force term and the inertial force term, which can also be expressed as a matrix related to the permeability coefficient tensor $K_{i j}$ and the non-Darcy coefficient tensor $\beta_{i j},|\mathbf{u}|$ is the modulus of flow velocity, $\left(K_{i j}^{*} /|\mathbf{K}|\right)$ is the inverse matrix of the equivalent permeability coefficient matrix, and $\beta_{i j}$ is the equivalent non-Darcy coefficient tensor.

Since the forward and reverse seepage characteristics of a single smooth fracture will not differ between Darcy and non-Darcy seepage conditions, for a fracture network composed of smooth single fractures, the fracture network's seepage characteristics under forward and reverse seepage will not be different. In other words, the permeability coefficient $K$ of the smooth fracture network will remain consistent in any state under the relative seepage direction (forward and reverse direction). For smooth fracture networks, the equivalent non-Darcy coefficient $\beta$ in the relative seepage direction obtained by equation (11) will also be consistent. The equivalent non-Darcy coefficient $\beta$ conforms to the tensor's symmetry, which can theoretically constitute the equivalent non-Darcy coefficient tensor $\beta_{i j}$ [64]. However, this paper's research shows that when $\operatorname{Re}>10$, the fracture seepage of a single rough fracture enters the nonDarcy seepage stage, and then the difference of forward and reverse seepage occurs. The quantitative description by th Forchheimer law (equation (9)) shows that, in the state of non-Darcy seepage, the permeability coefficient $k$ has nothing to do with the direction of seepage, and the nonDarcy coefficient $\beta$ is related to the direction of seepage. 
Therefore, for the fracture network composed of single rough fractures, the difference of the forward and reverse flow direction of the single rough fracture will also lead to the difference in the rough fracture network's relative flow direction. If equation (11) is used, the equivalent non-Darcy coefficient $\beta$ in the relative seepage direction will no longer be consistent and will no longer conform to the tensor's symmetry. So, for rough fracture networks, the applicability of equation (11) will be limited. This will also raise new problems and challenges for describing the rough fracture network's non-Darcy seepage characteristics accurately and quantitatively.

In the actual natural environment and engineering environment, the single fractures that make up the fracture network in the rock mass are rough. In the non-Darcy seepage state of these rough single fractures, the forward and reverse seepage directions' seepage characteristics will be different. How much do these differences affect the difference in the direction of seepage flow in the fracture network? In turn, will the difference in the flow direction of the rough fracture network for seepage flow and solute movement have much impact on the project? These issues need to be addressed by an in-depth research in the follow-up work.

\section{Summary and Conclusion}

This paper's primary purpose is to investigate the discrepancy between forward and reverse seepage characteristics of single rough fractures. The wavelet transform technique is used to decompose the fracture profile by multiple scales (multidecomposition levels). The approximate models of the detailed profiles with different frequencies (different decomposition levels) are obtained. The original profile model and eight approximate models are then numerically simulated with the Reynolds number varying from 0.001 to 1000 utilizing FVM (Finite Volume Method). Through the above research, the following conclusions can be drawn:

(1) The necessary condition for the various hydraulic characteristics of two directions in single rough fractures is nonlinear seepage. When $\operatorname{Re}<10$, the correlation between the pressure gradient and flow rate in this paper strictly satisfies the cubic law in all fracture models, and there is no difference between seepages in two directions. When $\operatorname{Re}>10$, the correlation between the pressure gradient and flow rate in this paper no longer strictly satisfies the cubic law in all fracture models. There is a discrepancy between the forward and reverse seepages only from the original fracture model to the 4th approximate fracture model. Still, there is no difference between seepages in two directions from the 5th to 8th approximate fracture model.

(2) The discrepancy between the forward and reverse hydraulic seepage characteristics of the single rough fracture is the different shapes and distribution of the eddy currents generated by the forward and reverse nonlinear seepage. In the nonlinear seepage state, from the original fracture model to the $3 \mathrm{rd}$ approximate fracture model, eddy currents' shape and location are different in the seepage of two directions. The region of eddy currents in both directions gradually narrows with the increase of the decomposition level. So, the discrepancy of nonlinear seepage characteristics in two directions is also gradually reduced.

(3) The secondary roughness provides space for the generation and development of eddy currents. Simultaneously, it provides a geometric basis for the discrepancy of hydraulic characteristics in two directions. In this paper, the 4th approximate profile is taken as the primary roughness. The sum of the first four detailed profiles $(D 1+\mathrm{D} 2+D 3+\mathrm{D} 4)$ is regarded as the secondary roughness. The difference between the effective apertures in the forward and reverse seepages, the difference between non-Darcy coefficients of two directions, and the comparison of local eddy currents show that the 4th approximate profile is the boundary point of whether there will be a discrepancy in the forward and reverse hydraulic characteristics.

In this paper, the difference between the forward and reverse nonlinear seepage flows under the single rough fracture's multiscale roughness was analyzed in detail. We adopt the fracture model whose upper and lower fracture profiles are the same, without considering different upper and lower fracture profiles in nature. Only a $2 \mathrm{D}$ fracture model is discussed in this paper. More complex 3D fracture models still need to be further studied. We will gradually carry out the above-unfinished researches in the succeeding stage.

\section{Data Availability}

The data used to support the findings of this study are available from the corresponding author upon request.

\section{Conflicts of Interest}

The authors declare that they have no conflicts of interest.

\section{Acknowledgments}

This work was supported by the National Key Research and Development Program of China (Grant no. 2018YFC1505306), the Major Program of the National Natural Science Foundation of China (Grant no. 41931295), and the General Program of the National Natural Science Foundation of China (Grant no. 41772340).

\section{References}

[1] J. Bear, C. F. Tsang, and G. De Marsily, Flow and Contaminant Transport in Fractured Rock, Academic Press, Cambridge, MA, USA, 2012.

[2] M. S. A. Perera, P. G. Ranjith, S. K. Choi, and D. Airey, "Numerical simulation of gas flow through porous sandstone 
and its experimental validation," Fuel, vol. 90, no. 2, pp. 547-554, 2011.

[3] C. W. MacMinn, M. L. Szulczewski, and R. Juanes, "CO2 migration in saline aquifers. Part 1. Capillary trapping under slope and groundwater flow," Journal of Fluid Mechanics, vol. 662, pp. 329-351, 2010.

[4] B. J. A. i. w. r. Berkowitz, "Characterizing flow and transport in fractured geological media," A Review, vol. 25, pp. 861-884, 2002.

[5] Z. Wang, S. Li, L. Qiao, and Q. Zhang, "Finite element analysis of the hydro-mechanical behavior of an underground crude oil storage facility in granite subject to cyclic loading during operation," International Journal of Rock Mechanics and Mining Sciences, vol. 73, pp. 70-81, 2015.

[6] L. P. Li, Z. Q. Zhou, S. C. Li, Y. G. Xue, Z. H. Xu, and S. S. Shi, "An attribute synthetic evaluation system for risk assessment of floor water inrush in coal mines," Mine Water \& the Environment, vol. 34, no. 3, pp. 288-294, 2015.

[7] Z. Dou, B. Sleep, H. Zhan, Z. Zhou, and J. Wang, "Multiscale roughness influence on conservative solute transport in selfaffine fractures," International Journal of Heat and Mass Transfer, vol. 133, pp. 606-618, 2019.

[8] S. H. Lee, K.-K. Lee, and I. W. Yeo, "Assessment of the validity of Stokes and Reynolds equations for fluid flow through a rough-walled fracture with flow imaging," Geophysical Research Letters, vol. 41, no. 13, pp. 4578-4585, 2014.

[9] M. E. Thompson and S. R. Brown, "The effect of anisotropic surface roughness on flow and transport in fractures," Journal of Geophysical Research: Solid Earth, vol. 96, no. B13, pp. 21923-21932, 1991.

[10] G. Grasselli, J. Wirth, and R. W. Zimmerman, "Surface parameters for quantifying the hydro-mechanical anisotropy of rock discontinuities," in Proceedings of the 10th ISRM Congress International Society for Rock Mechanics and Rock Engineering, Sandton, South Africa, 2003.

[11] C. Cao, Z. Xu, J. Chai, Y. Qin, and R. Tan, "Mechanical and hydraulic behaviors in a single fracture with asperities crushed during shear," International Journal of Geomechanics, vol. 18, no. 11, 2018.

[12] I. W. Yeo, M. H. De Freitas, and R. W. Zimmerman, "Effect of shear displacement on the aperture and permeability of a rock fracture," International Journal of Rock Mechanics and Mining Sciences, vol. 35, no. 8, pp. 1051-1070, 1998.

[13] H. Auradou, G. Drazer, J. P. Hulin, and J. Koplik, "Permeability anisotropy induced by the shear displacement of rough fracture walls," Water Resources Research, vol. 41, no. 9, 2005.

[14] N. Huang, R. Liu, and Y. Jiang, "Numerical study of the geometrical and hydraulic characteristics of 3D self-affine rough fractures during shear," Journal of Natural Gas Science and Engineering, vol. 45, pp. 127-142, 2017.

[15] D. F. Boutt, G. Grasselli, J. T. Fredrich, B. K. Cook, and J. R. Williams, "Trapping zones: the effect of fracture roughness on the directional anisotropy of fluid flow and colloid transport in a single fracture," Geophysical Research Letters, vol. 33, no. 21, pp. 1522-1534, 2006.

[16] L. Z. Xie, C. Gao, L. Ren, and C. B. Li, "Numerical investigation of geometrical and hydraulic properties in a single rock fracture during shear displacement with the Navier-Stokes equations," Environmental Earth Sciences, vol. 73, no. 11, pp. 7061-7074, 2015.

[17] M. B. Cardenas, D. T. Slottke, R. A. Ketcham, and J. M. Sharp, "Effects of inertia and directionality on flow and transport in a rough asymmetric fracture," Journal of Geophysical Research, vol. 114, 2009.
[18] F. D. Patton, Multiple Modes of Shear Failure in Rock 1st ISRM Congress, International Society for Rock Mechanics and Rock Engineering, Lisbon, Portugal, 1966.

[19] Y.-H. Lee, J. R. Carr, D. J. Barr, and C. J. Haas, "The fractal dimension as a measure of the roughness of rock discontinuity profiles," International Journal of Rock Mechanics and Mining Sciences \& Geomechanics Abstracts, vol. 27, no. 6, pp. 453-464, 1990.

[20] H. Xie, J.-A. Wang, and W.-H. Xie, "Fractal effects of surface roughness on the mechanical behavior of rock joints," Chaos, Solitons \& Fractals, vol. 8, no. 2, pp. 221-252, 1997.

[21] I. S. F. R. Mechanics, "Suggested methods for the quantitative description of discontinuities in rock masses," International Journal of Rock Mechanics and Mining Sciences, vol. 15, no. 6, pp. 319-368, 1978.

[22] L. Jing, E. Nordlund, and O. Stephansson, “An experimental study on the anisotropy and stress-dependency of the strength and deformability of rock joints," International Journal of Rock Mechanics and Mining Sciences \& Geomechanics Abstracts, vol. 29, no. 6, pp. 535-542, 1992.

[23] D. D. Kana, D. J. Fox, and S. M. Hsiung, "Interlock/friction model for dynamic shear response in natural jointed rock," International Journal of Rock Mechanics and Mining Sciences \& Geomechanics Abstracts, vol. 33, no. 4, pp. 371-386, 1996.

[24] Z. Y. Yang, C. C. Di, and K. C. Yen, "The effect of asperity order on the roughness of rock joints," International Journal of Rock Mechanics and Mining Sciences, vol. 38, no. 5, pp. 745-752, 2001.

[25] M. Sharifzadeh, "Evaluation of rock joint hydraulic aperture using wavelet theory," in Proceedings of the ISRM Regional Symposium-7th Asian Rock Mechanics Symposium, Seoul, Korea, October 2012.

[26] L. Zou, V. Cvetkovic, and L. Jing, "Roughness decomposition and effects on fluid flow in single rock fractures," in Proceedings of the ISRM International Symposium-8th Asian Rock Mechanics Symposium, Seoul, Korea, October 2014.

[27] L. Zou, L. Jing, and V. Cvetkovic, "Roughness decomposition and nonlinear fluid flow in a single rock fracture," International Journal of Rock Mechanics and Mining Sciences, vol. 75, pp. 102-118, 2015.

[28] M. Wang, Y.-F. Chen, G.-W. Ma, J.-Q. Zhou, and C.-B. Zhou, "Influence of surface roughness on nonlinear flow behaviors in 3D self-affine rough fractures: lattice Boltzmann simulations," Advances in Water Resources, vol. 96, pp. 373-388, 2016.

[29] B. G. Chae, Y. Ichikawa, G. C. Jeong, Y. S. Seo, and B. C. Kim, "Roughness measurement of rock discontinuities using a confocal laser scanning microscope and the Fourier spectral analysis," Engineering Geology, vol. 72, no. 3-4, pp. 181-199, 2004.

[30] A. Chamoli, A. Ram Bansal, and V. P. Dimri, "Wavelet and rescaled range approach for the Hurst coefficient for short and long time series," Computers \& Geosciences, vol. 33, no. 1, pp. 83-93, 2007.

[31] K. Khoshelham, D. Altundag, D. Ngan-Tillard, and M. Menenti, "Influence of range measurement noise on roughness characterization of rock surfaces using terrestrial laser scanning," International Journal of Rock Mechanics and Mining Sciences, vol. 48, no. 8, pp. 1215-1223, 2011.

[32] P. S. Pradhan, R. L. King, N. H. Younan, and D. W. Holcomb, "Estimation of the number of decomposition levels for a wavelet-based multiresolution multisensor image fusion," IEEE Transactions on Geoscience and Remote Sensing, vol. 44, no. 12, pp. 3674-3686, 2006. 
[33] Y. Mirzaeian, Hydromechanical Coupling Behavior of a Single Rock Joint under Normal and Shear Load [Doctoral Dissertation, Amirkabir University of Technology of Tehran, Tehran, Iran, 2008.

[34] S. G. Mallat, "A theory for multiresolution signal decomposition: the wavelet representation," IEEE Transactions on Pattern Analysis and Machine Intelligence, vol. 11, no. 7, pp. 674-693, 1989.

[35] M. B. Cardenas, D. T. Slottke, R. A. Ketcham, and J. M. Sharp, "Navier-Stokes flow and transport simulations using real fractures shows heavy tailing due to eddies," Geophysical Research Letters, vol. 34, no. 14, pp. 176-192, 2007.

[36] M. Javadi, M. Sharifzadeh, and K. Shahriar, "A new geometrical model for non-linear fluid flow through rough fractures," Journal of Hydrology, vol. 389, no. 1-2, pp. 18-30, 2010.

[37] S. H. Lee, I. W. Yeo, K.-K. Lee, and R. L. Detwiler, "Tail shortening with developing eddies in a rough-walled rock fracture," Geophysical Research Letters, vol. 42, no. 15, pp. 6340-6347, 2015.

[38] J. Bouquain, Y. Méheust, D. Bolster, and P. Davy, "The impact of inertial effects on solute dispersion in a channel with periodically varying aperture," Physics of Fluids, vol. 24, no. 8, pp. 186-327, 2012.

[39] T. Koyama, I. Neretnieks, and L. Jing, "A numerical study on differences in using Navier-Stokes and Reynolds equations for modeling the fluid flow and particle transport in single rock fractures with shear," International Journal of Rock Mechanics and Mining Sciences, vol. 45, no. 7, pp. 1082-1101, 2008.

[40] J. Qian, M. Liang, Z. Chen, and H. Zhan, "Eddy correlations for water flow in a single fracture with abruptly changing aperture," Hydrological Processes, vol. 26, no. 22, pp. 3369-3377, 2012.

[41] J. Qian, L. Ma, H. Zhan, Q. Luo, X. Wang, and M. Wang, "The effect of expansion ratio on the critical Reynolds number in single fracture flow with sudden expansion," Hydrological Processes, vol. 30, no. 11, pp. 1718-1726, 2016.

[42] R. Liu, B. Li, and Y. Jiang, "Critical hydraulic gradient for nonlinear flow through rock fracture networks: the roles of aperture, surface roughness, and number of intersections," Advances in Water Resources, vol. 88, pp. 53-65, 2016.

[43] R. W. Zimmerman, A. Al-Yaarubi, C. C. Pain, and C. A. Grattoni, "Non-linear regimes of fluid flow in rock fractures," International Journal of Rock Mechanics and Mining Sciences, vol. 41, pp. 163-169, 2004.

[44] M. Javadi, M. Sharifzadeh, K. Shahriar, and Y. J. W. R. R. Mitani, Critical Reynolds Number for Nonlinear Flow through Rough-walled Fractures: The Role of Shear Processes, Wiley, Hoboken, NJ, USA, 2014.

[45] S. Briggs, B. W. Karney, and B. E. Sleep, "Numerical modeling of the effects of roughness on flow and eddy formation in fractures," Journal of Rock Mechanics and Geotechnical Engineering, vol. 9, no. 1, pp. 105-115, 2017.

[46] B. Li and Y. Jiang, "Quantitative estimation of fluid flow mechanism in rock fracture taking into account the influences of JRC and Reynolds number," Journal of MMIJ, vol. 129, no. 7, pp. 479-484, 2013.

[47] X. Qian, C. Xia, Y. Gui, X. Zhuang, and Q. Yu, "Study on flow regimes and seepage models through open rough-walled rock joints under high hydraulic gradient," Hydrogeology Journal, vol. 27, no. 4, pp. 1329-1343, 2019.

[48] Y. Zhang, J. Chai, C. Cao, and T. Shang, "Combined influences of shear displacement, roughness, and pressure gradient on nonlinear flow in self-affine fractures," Journal of Petroleum Science and Engineering, vol. 198, 2021.

[49] Y. Qin, M. Li, Y. Li, W. Ma, and H. Zhou, "Effects of nylon fiber and nylon fiber fabric on the permeability of cracked concrete," Construction Building Materials, vol. 274, p. 121786, 2021.

[50] P. Forchheimer, "Wasserbewegung durch boden," Z. Ver. Deutsch, Ing.vol. 45, pp. 1782-1788, 1901.

[51] Y.-F. Chen, J.-Q. Zhou, S.-H. Hu, R. Hu, and C.-B. Zhou, "Evaluation of Forchheimer equation coefficients for nonDarcy flow in deformable rough-walled fractures," Journal of Hydrology, vol. 529, pp. 993-1006, 2015.

[52] A. Nowamooz, G. Radilla, and M. Fourar, "Non-Darcian twophase flow in a transparent replica of a rough-walled rock fracture," Water Resources Research, vol. 45, no. 7, pp. 4542-4548, 2009.

[53] M. G. Sidiropoulou, K. N. Moutsopoulos, and V. A. Tsihrintzis, "Determination of Forchheimer equation coefficients a and b," Hydrological Processes, vol. 21, no. 4, pp. 534-554, 2010.

[54] X. Zhang, J. Chai, Y. Qin, J. Cao, and C. Cao, "Experimental study on seepage and stress of single-fracture radiation flow," Ksce Journal of Civil Engineering, vol. 23, no. 3, pp. 1132-1140, 2019.

[55] Y. Zhang and J. Chai, "Effect of surface morphology on fluid flow in rough fractures: a review," Journal of Natural Gas Science and Engineering, vol. 79, Article ID 103343, 2020.

[56] T. Belem, F. Homand-Etienne, and M. Souley, "Quantitative parameters for rock joint surface roughness," Rock Mechanics and Rock Engineering, vol. 33, no. 4, pp. 217-242, 2000.

[57] G. Zhang, M. Karakus, H. Tang, Y. Ge, and L. Zhang, "A new method estimating the 2D Joint Roughness Coefficient for discontinuity surfaces in rock masses," International Journal of Rock Mechanics and Mining Sciences, vol. 72, pp. 191-198, 2014.

[58] G. Grasselli, J. Wirth, and P. Egger, "Quantitative threedimensional description of a rough surface and parameter evolution with shearing," International Journal of Rock Mechanics and Mining Sciences, vol. 39, no. 6, pp. 789-800, 2002.

[59] G. Grasselli, "Manuel rocha medal recipient shear strength of rock joints based on quantified surface description," Rock Mechanics and Rock Engineering, vol. 39, no. 4, p. 295, 2006.

[60] B. S. A. Tatone and G. Grasselli, "A new 2D discontinuity roughness parameter and its correlation with JRC," International Journal of Rock Mechanics and Mining Sciences, vol. 47, no. 8, pp. 1391-1400, 2010.

[61] R. Liu, B. Li, Y. Jiang, and L. Yu, "A numerical approach for assessing effects of shear on equivalent permeability and nonlinear flow characteristics of 2-D fracture networks," Advances in Water Resources, vol. 111, pp. 289-300, 2018.

[62] Q. Yin, H. Jing, R. Liu, G. Ma, L. Yu, and H. Su, "Experimental study on stress-dependent nonlinear flow behavior and normalized transmissivity of real rock fracture networks," Geofluids, vol. 2018, Article ID 8217921, 16 pages, 2018.

[63] V. A. Garanzha, V. N. Konshin, S. L. Lyons, D. V. Papavassiliou, and G. Qin, "Validation of non-Darcy well models using direct numerical simulation," in Numerical Treatment of Multiphase Flows in Porous Media, Z. Chen, R. E. Ewing, and Z. C. Shi, Eds., pp. 156-169, Springer, Berlin, Germany, 2000.

[64] Y. Niu, Y. Wang, K. Yu, and D. Feng, "Non-Darcy seepage rev and non-Darcy coefficient tensor in fracture network," Journal of Hydraulic Engineering, vol. 51, no. 4, pp. 468-478, 2020. 